Federal Reserve Bank of Dallas

Globalization and Monetary Policy Institute

Working Paper No. 24

http://www.dallasfed.org/assets/documents/institute/wpapers/2009/0024.pdf

\title{
How Successful is the G7 in Managing Exchange Rates?*
}

\author{
Marcel Fratzscher \\ European Central Bank
}

January 2009

\begin{abstract}
The paper assesses the extent to which the Group of Seven (G7) has been successful in its management of major currencies since the 1970s. Using an event-study approach, the paper finds evidence that the $\mathrm{G} 7$ has been overall effective in moving the US dollar, yen and euro in the intended direction at horizons of up to three months after G7 meetings, but not at longer horizons. While the success of the $G 7$ is partly dependent on the market environment, it is also to a significant degree endogenous to the policy process itself. The findings indicate that the reputation and credibility of the G7, as well as its ability to form and communicate a consensus among individual G7 members, are important determinants for the G7's ability to manage major currencies. The paper concludes by analyzing the factors that help the $\mathrm{G} 7$ build reputation and consensus, and by discussing the implications for global economic governance.
\end{abstract}

JEL codes: F31, F33, F50

\footnotetext{
* Marcel Fratzscher, European Central Bank, Kaiserstrasse 29, D-60311 Frankfurt/Main, Germany. +49-69- 1344- 6871. Marcel.Fratzscher@ecb.int. I would like to thank Ettore Dorrucci, Michael Ehrmann, Michael Fidora, Randy Henning, David-Jan Jansen, Benjamin Klaus, Arnaud Mehl, Frank Moss, Georges Pineau, Giulia Sestieri, Martin Skala, Roland Straub, and Christian Thimann for comments and discussions, as well as Martin Skala for help with some of the data series. The views expressed in this paper are those of the author and do not necessarily reflect the views of the European Central Bank, the Federal Reserve Bank of Dallas or the Federal Reserve System.
} 


\section{Introduction}

Created in 1975 after the demise of the Bretton Woods system, the Group of Seven (G7) of key industrialized economies is one of the most influential institutions for international policy coordination and global economic governance. A central, if not the single most important area of economic policy coordination for the G7 has been the management of major exchange rate configurations. The G7 has arguably played a central role in various episodes in this regard since its establishment, such as in the marked depreciation of the US dollar following the G7 Plaza Accord in 1985 and other episodes in the 1990s.

Given the importance of its members for the global economy, G7 meetings and their accompanying policy statements about economic issues receive considerable scrutiny, in the media as well as among policy-makers and financial market participants. Yet a debate has emerged in recent years about its effectiveness in managing major exchange rate configurations, and also about its future in a changing world in which other economies, such as among emerging markets, have become of global systemic importance.

Given this debate, it is important to understand how effective the G7 has been as an institution. Using an event-study methodology, the objective of the paper is to assess how successful the G7 has been in managing major exchange rates since the 1970s. ${ }^{1}$ Moreover, the paper analyses if and when the G7 has succeeded in forming a consensus among its members and in building a reputation of credibility. Consensus among its members and a high degree of credibility may not only be final objectives by themselves, but they may be important tools and prerequisites for the $\mathrm{G} 7$ to achieve its exchange rate objectives. The paper develops novel proxies for $\mathrm{G} 7$ consensus and reputation, and investigates how instrumental these have been in helping the $\mathrm{G} 7$ attain its objectives.

A fundamental conceptual issue is how and why statements by the G7 should have any effect on currency values at all, and through what channels these effects occur. There is a rapidly growing literature on the role of communication by policy-makers in managing market expectations, foremost in the field of monetary economics, ${ }^{2}$ but increasingly also for exchange rates. ${ }^{3}$ The issue is that many G7 statements may not come as a surprise to financial markets; so why should they have any impact on currency values? The answer is that important policy statements, such as G7 communiqués, may not contain new information, yet they may still exert a marked effect on markets through what Sarno and Taylor (2001) coined

\footnotetext{
${ }^{1}$ The focus of the paper is specifically on G3 exchange rates (US dollar, yen, and Deutsche mark before 1999 and euro since 1999), though the range of issues covered by the G7 is much broader and goes beyond the sphere of economic policy. Moreover, the paper does not analyse the response of the other G7 currencies - the Canadian dollar or the UK pound - mainly because these have never been the subject of G7 communiqués.

${ }^{2}$ The evidence in this literature points at a remarkable evolution over the past decade in central banks' ability to manage expectations. See Bernanke (2004), Blinder (2004) and Woodford (2005) for three prominent exposures, and Blinder at al. (2008) for a comprehensive survey.

${ }^{3}$ Examples are Beine et al. (2006), Fratzscher (2004, 2006), and Jansen and De Haan (2007). There is also a large literature on actual FX interventions, with evidence that such interventions do influence exchange rates, although this effect depends on a multitude of factors. Dominguez and Frankel (1993) is the seminal paper that started much of this literature, with other important contributions including Fatum and Hutchison (2003), Ito (2002), Kearns and Rigobon (2004), Neely (1995, 2005), Sarno and Taylor (2001), Taylor (2004) and Vitale (1999).
} 
a coordination channel. For this channel, currency values may deviate from underlying economic fundamentals due to a coordination failure among market participants, while statements by policy-makers may function as a device to coordinate beliefs and make markets revert back to more sustainable levels. There is indeed evidence that such a coordination channel is at work in FX markets (e.g. Taylor 2004, and Fratzscher 2008).

Turning to the empirical results of the paper, the evidence suggests that G3 currencies have moved in the direction intended by the $\mathrm{G} 7$ in about $60 \%$ of the cases after one to six months and even in about $80 \%$ of the cases after one year. It may be tempting to infer from this that the G7 is highly successful. However, such a conclusion may be misleading as it does not necessarily mean that the G7 communiqué had any causal effect on exchange rates. It may well be that G7 policy-makers are simply pointing out major currency misalignments in their communiqués, and that exchange rates would have adjusted anyway through market forces even without G7 statements.

The paper tries to address this point by extracting counter-factual exchange rate predictions, i.e. how exchange rates would have evolved if the G7 had not issued a statement about intended currency configurations. It does so by employing a factor model, following Pojarliev and Levich (2007), which uses a trading rule with four factors - a carry factor of interest rate differentials, a trend factor of the past exchange rate trend, a value factor of currency misalignment, and a volatility factor. Despite the difficulty of predicting currency values, especially at shorter horizons (e.g. Cheung et al. 2005), it seems worthwhile to try and identify an alternative to the random walk counter-factual, in particular as the G7 statements are often made in market conditions of stress and major misalignments. In fact, one rationale for the choice of this model is that its factors (specifically the degree of misalignment, and volatility) are found to reflect closely the motivation behind G7 communiqués.

Overall, while the random walk benchmark implies that the G7 may have been highly effective in moving G3 currencies at horizons up to one year, the counterfactual based on the factor model entails that G7 statements have had a causal effect in moving G3 exchange rates only at shorter horizons of up to a few months, but not beyond. However, even if one takes the factor model as the preferred benchmark, one interpretation of the findings is that the G7 indeed correctly points out major currency misalignments, and by doing so helps facilitate and accelerate the convergence process of misaligned currencies back to more sustainable levels. In fact, it may be unrealistic and possibly not even the intention of the G7 to have a long-lasting effect on currency values.

The final part of the paper's analysis turns to the determinants for G7 success in managing major exchange rates. The main thrust of the academic literature is that the success of policymakers in managing expectations crucially depends on their credibility, as well as their ability to provide clear and consistent information to financial markets. Applying this argument to the G7 means that its ability to manage G3 currencies may depend both on its reputation and on its ability to communicate clearly with markets. 
Measuring the reputation and credibility of the G7 is tricky, as it requires gauging the public's view of the G7. Building on a broad literature in linguistics, the paper constructs a novel measure of G7 reputation based on what linguists call the 'semantic orientation' of the media coverage about the G7. The idea is to extract a normative assessment from print media reports (newspapers, newswire reports, articles) using content analysis, and based on a lexicon that categorizes adjectives into having a positive or negative connotation with the G7. Moreover, the paper uses various measures to proxy the intensity and the cacophony of G7 statements and the surrounding communication of G3 policy-makers.

The empirical analysis yields three main findings. First, G7 reputation is of fundamental importance for G7 effectiveness in managing exchange rates. Measuring G7 reputation before respective meetings in order to avoid the endogeneity of reputation to success, the results indicate that G7 statements move G3 currencies in the desired direction in as many as about $80 \%$ of the cases when the $\mathrm{G} 7$ enjoyed a high degree of credibility. A second factor is the degree of cacophony among G3 policy-makers. G7 meetings that are followed by a period in which G3 policy-makers communicate a consensus among themselves are associated with a high success ratio in moving exchange rates in the desired way, but not if such consensus is missing. One interpretation is that a G7 message may not reach financial market participants in an environment in which cacophony among individual G3 policy-makers is high.

A third set of factors is that the success ratio of G7 communiqués is higher when they are supported by actual interventions of G3 authorities. This appears to apply mainly to the earlier period of the G7 as such intervention activity has decreased markedly after 1995, at least for the US and the European countries. The empirical analysis also controls for other policy factors, such as interest rate differentials and the direction of monetary policy, implying that reputation and communication influence the effectiveness of the G7 as channels independent of whether or not they are supported by actual interventions and monetary policy.

These empirical findings have some direct and some indirect policy implications. They imply that the G7 has been accurate in identifying currency misalignments as well as reasonably successful in moving G3 currencies in the desired way, at least over a time horizon of up to a few months subsequent to G7 meetings. This suggests that the G7 has played a fairly effective role in facilitating and accelerating the convergence process of misaligned currencies back to more sustainable levels. One key implication of the findings is that while the success of the G7 is certainly partly dependent on market forces, it is also to a considerable extent endogenous to the policy process and to G7 policy-makers themselves. This means that the success of the G7 is influenced by the ability of policy-makers to form and communicate a consensus, as well as their ability to build and maintain a credible reputation of the G7 as an effective policy institution.

The paper is related to two strands of the literature. Much of the scant work on the G7 has concentrated on its institutional role within the international monetary architecture (Bergsten and Henning 1996, Boughton 2001; Sobel and Stedman 2006), with some work analyzing specific G7 episodes from an historical perspective (Putnam and Henning 1989, Von 
Furstenberg, and Daniels 1991, Henning 2008). By contrast, the Jurgensen report (Jurgensen, 1993) assessed actual FX interventions in the G7 context and argued that interventions may be effective under disorderly market conditions. Klein et al. (1991) focus on the G7 Plaza agreement of 1985, showing that G3 currencies responded more strongly to the US trade balance and interpreting this as that "the Plaza agreement marked a turning point in the coordination of economic policies" (p. 750). Yet, no work to date has attempted to systematically assess the G7 in managing major exchange rates. This is the intended contribution of the present paper.

More generally, the paper broadly relates to the literature on the role of global institutions such as the WTO and whether it has raised global trade (Rose 2004), or the IMF and whether its lending induces moral hazard among borrowers and investors (e.g. Barro and Lee 2005, Dreher et al. 2007, Jeanne and Zettelmeyer 2001, Mussa 1999, and Rogoff 2002), or on the political economy of the decision-making process in institutions such as the UN Security Council (e.g. Kuziemko and Werker 2006).

The paper proceeds by outlining the methodology and the data used in the empirical analysis in section 2. Section 3 describes the model specification of the event-study approach and presents the findings for the actual success and the perceived success of G7 communiqués. Section 4 discusses the implications of these findings and analyses what shapes G7 reputation and consensus. Conclusions and a discussion of policy implications follow in section 5 .

\section{Methodology and Data}

This section describes the methodology and data for the empirical analysis, starting with how G7 statements are identified (section 2.1) and classified as successful or not in terms of their exchange rate intentions (sections 2.2 and 2.3). I then outline the methodology of how I measure G7 reputation (section 2.4), and the database on the communication by individual G3 policy-makers around G7 meetings in order to identify the clarity and cacophony of G3 communication (section 2.5).

\subsection{Identifying and classifying G7 statements on exchange rates}

The G7 was established in 1975 by the heads of state or government of major industrialized countries, of what was initially the Group of Six - France, Germany, Japan, the United Kingdom, and the United States - with Canada joining in 1976. The goal of this group has mainly been to foster cooperation and coordination on economic policy, but also more widely on other issues such as security and energy. ${ }^{4}$ Being in charge of most economic issues, the finance ministers and central bank governors initially met in conjunction with the heads of

\footnotetext{
${ }^{4}$ The following quote from the G6 declaration in Rambouillet, France, on 17 November 1975 illustrates these objectives: "We came together because of shared beliefs and shared responsibilities. ... we intend to play our own full part and strengthen our efforts for closer international cooperation... With regard to monetary problems, we affirm our intention to work for greater stability. ..., our monetary authorities will act to counter disorderly market conditions, or erratic fluctuations, in exchange rates."
} 
state. Since 1985, finance ministers and governors meet separately, about three to four times per year, and issue their own communiqués.

While various G7 statements over time also raise other issues, such as trade, inflation or financial markets, my focus is more narrowly on exchange rates. Exchange rates have basically always been an important element of G7 deliberations and have always been discussed in the G7 communique (with the exception of the 1977 meeting). ${ }^{5}$ The G7 language on exchange rates varies from a few sentences emphasizing "cooperation" and "monitoring", to more extensive discussions stressing concerns and the possibility of interventions. The following quote from the 1985 Plaza Accord provides an illustration:

"The Ministers and Governors agreed that exchange rates should play a role in adjusting external imbalances. In order to do this, exchange rates should better reflect fundamental economic conditions than has been the case. They believe that agreed policy actions must be implemented and reinforced to improve the fundamentals further, and that in view of the present and prospective changes in fundamentals, some further orderly appreciation of the main non-dollar currencies against the dollar is desirable. They stand ready to cooperate more closely to encourage this when to do so would be helpful."

(G5 communiqué, New York, USA, 22 September 1985 [Plaza Accord] $)^{6}$

The starting point is to extract the views and intentions of the G7 about exchange rates from each G7 communiqué, which is usually released on the day of the meeting. Focusing on those statements in which there is an indication about the desired direction of currencies, the objective of the first part of the paper is to analyze how exchange rates have moved during the subsequent 12 months. To do so, each of the 76 communiqués since 1975 is coded of whether or not it included a statement on the desired level of exchange rates, and what the intended direction is. The empirical analysis concentrates on the three main, or "G3" currencies (US dollar, yen, and Deutsche mark before 1999 and euro since 1999). For instance, the Plaza Accord quoted above clearly shows the intention of the G7 to weaken the US dollar against the Deutsche mark and the yen. The classification yields 29 G7 meetings with an indication on exchange rate levels, which allows inferring desired directional changes for 58 currency pairs, though for various parts of the analysis below the analysis includes all meetings and G3 bilateral currencies for a total of 228 observations.

\section{2 "Perceived" success of the G7}

The main challenge of assessing whether G3 currencies moved in the desired direction subsequent to G7 statements is that exchange rates tend to be highly volatile. Using an eventstudy chart, Figure 1 illustrates this point by plotting the distribution of the average change

\footnotetext{
${ }^{5}$ I will refer to the statements of the finance ministers and governors, rather than statements issued by the heads of state or other ministerial meetings, as "G7 communiqués" throughout the paper.

${ }^{6}$ The ministers and governors of Canada and Italy did not join the Plaza meeting, but joined in 1986.
} 
across the three G3 currency pairs around G7 meetings (from 12 months before to 12 months afterwards). Importantly, exchange rate movements in this figure are "signed", i.e. a positive change/increase in an exchange rate after G7 meetings shows a move of the currency in the direction intended by the $\mathrm{G} 7$, and a decrease is a change in the undesired direction.

\section{Figure 1}

Three points are apparent from this chart. The first is that G3 currencies tend overwhelmingly to move in the desired direction after G7 meetings. The more time elapses, the more often do currencies do so - in fact in more than $80 \%$ of the cases after 12 months have G3 currencies done so, as indicated by the deciles in the chart. I will return in detail to this issue below. A second finding is that G7 statements are clearly "leaning against the wind", i.e. they try to reverse the trend during the 12 months before G7 meetings. This is an important point because it suggests that the intention of the G7 is endogenous to past exchange rate developments, an issue which will be addressed in section 3.2. The third point apparent from the figure is the large degree of heterogeneity in currency movements - the difference between the $10^{\text {th }}$ percentile and the $90^{\text {th }}$ percentile, for instance, is more than $20 \%$ after 4 months and more than $30 \% 12$ months after G7 meetings.

This heterogeneity and volatility in exchange rates thus makes it difficult to draw a statistical inference about the effect of G7 meetings when using time-series approaches. To shut down this noise of high-frequency movements in currencies, the paper employs an event-study approach, based on MacKinlay (1997), Humpage (1999) and Fratzscher (2008). The essence of this approach is to transform currency movements over particular time horizons into a binary variable: a move in the direction intended by the G7 statement - a "success" - and a change in the opposite direction of what was desired - a "failure". Using a non-parametric sign test, this transformation than allows testing to what extent G7 communiqués are successful in moving G3 currencies in the desired direction.

More formally, the "direction" criterion tests whether or not a bilateral exchange rate movement over the post-G7 window ( $\left.r^{\text {post }}\right)$ relative to a specific benchmark $\left(\overline{r^{\text {post }}}\right)$ is in the desired direction of the $\mathrm{G} 7\left(I^{G 7}\right)$. Hence, an exchange rate change under the direction criterion is defined as a success if:

$$
\left(r^{\text {post }}>\overline{r^{\text {post }}}, I^{G 7}>0\right) \text { or }\left(r^{\text {post }}<\overline{r^{\text {post }}}, I^{G 7}<0\right)
$$

and otherwise as a failure. As indicated above, many interventions are of the "leaning-againstthe-wind" type by trying to reverse prior exchange rate movements. The second criterion is therefore the "reversal" criterion, which tests whether the G7 oral intervention succeeds in appreciating the currency after the G7 statement if it was depreciating before, or in depreciating it when it was appreciating before: 


$$
\left(r^{\text {post }}>\overline{r^{\text {post }}}, I^{G 7}>0 \text { iff } r^{\text {pre }}<0\right) \text { or }\left(r^{\text {post }}<\overline{r^{p o s t}}, I^{G 7}<0 \text { iff } r^{\text {pre }}>0\right)
$$

Under the assumption that the actual exchange rate change is never exactly equal to the counter-factual, a non-parametric sign test is employed to test whether the number of identified successes $\left(n_{+}\right)$is larger than 0.5 , or $50 \%$, or in other words, is larger than the number of failures $\left(n_{-}\right)$. The null hypothesis is thus $n_{+} \sim \operatorname{binomial}(n, p=0.5)$, with $n$ as the total number of events.

The critical issue is how to identify the benchmark $\left(\overline{r^{p o s t}}\right)$. In other words, one can talk about an "actual success" of a G7 intervention only to the extent that one can identify a causal effect of a G7 statement on exchange rates. Hence a key difficulty in assessing G7 success is to know the counter-factual, i.e. how exchange rates would have evolved if the G7 had not issued a statement about intended currency configurations.

At short horizons, such as a few days or a few weeks, it may be fair to assume that an exchange rate is indistinguishable from a random walk. And much of the empirical literature confirms that this is indeed a reasonable proxy for short horizons. Hence, the random walk as the counter-factual implies that $\overline{r^{\text {post }}}=0$. I refer to the assessment of the G7 against the random walk benchmark as "perceived" success throughout the paper because it reflects what the public perceives and what we can observe. For instance, the Plaza Accord discussed above was followed by a depreciation of the US dollar against the yen and the Deutsche mark - as indeed intended by the G7 - though one may argue that this was not a causal effect of the G7 statement and policies, but was just a correction of an overvaluation of the US dollar. Hence, this episode may have been perceived as a success of the G7 as currencies moved in the desired direction, but may say nothing about causality.

\section{3 "Actual" success of the G7}

The question thus becomes what the appropriate choice of counter-factual is in order to identify a causal effect of the G7 on G3 exchange rate configurations. In particular, even if the random walk is a fairly good proxy at shorter horizons of a few days or weeks, this is unlikely to be the case at longer horizons.

The large literature on exchange rate forecasting, both in sample and out of sample, shows how difficult it is to predict exchange rates reliably, in particular at short horizons. The preference of the present paper is to use a factor model to extract an alternative counterfactual for currency movements after G7 meetings. This factor model is based on a simple benchmark of currency trading, following closely the specification of Pojarliev and Levich (2007), ${ }^{7}$ rather than using a model based on broader macroeconomic fundamentals, partly

\footnotetext{
${ }^{7}$ The objective of Pojarliev and Levich (2007) is very different from the one in the present paper, as they analyse how different factors are related to the alpha, or excess returns, of a set of individual currency fund managers.
} 
because of data issues and partly because forecasting rules based on the latter have been shown to perform rather poorly at horizons of less than one year (see e.g. Chinn et al. 2004). Moreover, an important reason for this choice is that the model's factors reflect quite closely the underlying motivation behind G7 communiqués, an issue to which I will return below.

I specify the factor model with four factors, as in Pojarliev and Levich (2007). The first factor is a carry factor of short-term (money market) interest rate differentials between the two countries of a currency pair. As e.g. also shown in Clarida and Waldman (2007), positive interest rate differentials tend to be associated with exchange rate appreciation, in line with the evidence of a forward discount bias. The second factor is a trend factor, measuring the past movement of the nominal exchange rate over the past $k$ periods. One would expect a positive relation, in line with some trend persistence in currency movements. The third is a value factor of currency misalignment, measured as the deviation of the current spot exchange rate from its average level over the past five years. ${ }^{8}$ The prior is that a misaligned exchange rate should tend to mean revert, and that this effect is stronger the longer the time horizon $\mathrm{k}$. The fourth factor is a volatility factor, using the ratio of realized volatilities of the respective effective exchange rates of the past $\mathrm{k}$ periods. The standard factor model looks as follows:

$$
r_{t+k}=\alpha^{k}+\sum_{i} \beta_{i}^{k} F_{i, t}+\varepsilon_{t}
$$

with $r_{t+k}$ as the realized exchange rate change over the future $\mathrm{k}$ periods. The factor model hence tries to relate today's factors $\mathrm{F}_{\mathrm{i}, \mathrm{t}}$ to currency movements over the next k periods. My modeling strategy is as follows. In the first step, the factor model is estimated in sample, but importantly, only for control time periods in which there were no G7 statements with an indication on exchange rate levels - which e.g. was the case in the late 1970s, early 1990s and early 2000s. This limitation to estimating the factor model (3) only for the control period is important because the objective is to identify the true relationship between the factors and exchange rates in the absence of $\mathrm{G} 7$ interventions. ${ }^{9}$

The second step is then to extract from the estimated factor model (3) the predicted exchange rate movements during the treatment sample, i.e. for the periods with $\mathrm{G} 7$ statements:

$$
E_{t}^{F} \boldsymbol{\leftrightarrow}_{t+k}=\hat{\alpha}^{k}+\sum_{i} \hat{\beta}_{i}^{k} F_{i, t}
$$

These forecasts are constructed for the day before a $G 7$ statement, i.e. the values of the factors $F_{i}$ are taken on the day before a G7 meeting and forecasts for exchange rate changes for the

\footnotetext{
${ }^{8}$ This is admittedly a crude proxy for currency misalignment. However, using more sophisticated measures based on behavioural or fundamental equilibrium exchange rate concepts is not feasible in this context with high frequency data. Moreover, the empirical estimates proved quite robust to the choice of alternative lengths in the reference period.

${ }^{9}$ The assumption here is that the only element that distinguishes the control sample from the treatment sample is the occurrence of G7 statements. This is of course a simplifying assumption, and e.g. monetary policy and actual FX intervention activity may also differ across the two samples. I try to test for the influence of these elements directly below in the part on the determinants of G7 success.
} 
subsequent periods $k$ are then extracted using the estimated coefficients from (3). The time horizons vary from one day (1D) to twelve months (12M). Model (3) is estimated for each horizon separately, so that the estimated coefficients are different for each forecast horizon. ${ }^{10}$

Hence, the counter-factual for currency movements after G7 meetings derived from the factor model is $\overline{r^{\text {post }}}=E_{t}^{F} r_{t+k}$. Using these forecasts from the factor model as the counter-factual allows identifying what I call throughout the paper the "actual" success of G7 interventions, as opposed to the "perceived" success with the random walk as counter-factual, because it attempts to identify the true, actual effect of G7 statements on currencies while controlling for market factors.

The caveats and limitations that apply to this and any effort to extract an alternative counterfactual for G3 currency movements cannot be stressed enough. However, it seems worthwhile the effort to try and identify an alternative to the random walk counter-factual, in particular as the $\mathrm{G} 7$ statements are often made in market conditions of stress and major misalignments.

Table 1

Moreover, specifying the counter-factual using such a factor model based on market factors also allows discussing the issue of endogeneity of G7 statements. The content of G7 communiqués are clearly not random and are responsive to market developments. To illustrate this point, I test whether the probability of the G7 expressing a view on a particular G3 currency pair is related to the four factors of the above factor model. Table 1 shows the point estimates of a multinomial logit estimation with the dependent variable being whether a G7 communiqué intends to strengthen a particular currency pair $\left(\mathrm{y}_{\mathrm{t}}=+1\right)$, weaken a currency pair $\left(\mathrm{y}_{\mathrm{t}}=-1\right)$, as compared to it expressing no view on that particular G3 bilateral exchange rate $\left(y_{t}=0\right)$. The results suggest that the content of $G 7$ statements is indeed closely linked to the misalignment of a currency pair - with the G7 pushing for a strengthening of a currency in periods when it is undervalued, and vice versa - as well as to the volatility of the currency. It is only marginally related to interest rate differentials and past exchange rate trends, though the signs of both variable are what one would expect.

I do not delve deeper into this analysis as the primary objective of the paper is not to identify the economic and political reasons for the tone or content of a particular G7 statement, but rather to understand how a given statement affects exchange rates. To do this, it is crucial to identify those financial market factors that influence currency values at a particular point in time, and the factor model presented above seems to be a reasonable choice to do so.

\footnotetext{
${ }^{10}$ To illustrate how the forecasts of the factor model compare to alternative models, Figure A.1 shows the forecasts for the US dollar - euro exchange rate on 1 May 2008 from the factor model, as well as survey forecasts - based on Bloomberg surveys of 50-60 market participants - and forecasts derived from forward contracts. Figure A.2 provides the parameter estimates of the factors at different horizons and the goodness of fit, indicating that the factor model has a fairly good fit beyond a horizon of six months. The main point is that forecasts from the factor model seem sensible, yielding similar forecasts to those of the survey based measures.
} 


\subsection{G7 reputation and credibility}

Building and maintaining a high level of reputation and credibility may not only be an objective in itself for the G7, but it may also be an important determinant for the success or failure for the $\mathrm{G} 7$ to achieve its exchange rate objectives. ${ }^{11}$

The purpose for the analysis of G7 effectiveness is therefore to construct a proxy for the G7's public reputation and credibility. This is a difficult task as there is no such readily available proxy. I construct such a measure by using a simple algorithm that allows extracting a normative assessment of the G7 from the print media coverage around G7 meetings. This methodology stems from linguistics, and the intersection of linguistics and computer science; and extracts a normative score, or semantic orientation (SO), for a particular phrase. ${ }^{12}$

A phrase has a positive semantic orientation when identified adjectives or adverbs have a positive connotation and have a close association with the phrase under consideration (e.g. "The G7 has been successful in its attempt..."), and a negative semantic orientation when these adjectives or adverbs have a negative connotation (e.g. "The G7 has been ineffective in its efforts...”). The PMI-IR algorithm employed uses Pointwise Mutual Information (PMI) and Information Retrieval (IR), which determines the semantic orientation of the phrase under consideration through its proximity with positive reference words relative to its proximity with negative reference words. The PMI of a phrase (e.g. "Group of Seven") with a particular word with a positive connotation ( $p w o r d$ ) in a given piece of text is defined as:

$$
P M I(\text { phrase }, \text { pword })=\log \left(\frac{\operatorname{prob}(\text { phrase \& pword })}{\text { prob }(\text { phrase }) * \operatorname{prob}(\text { pword })}\right)
$$

with prob(phrase \& pword) the probability that these two co-occur in the text, and prob(pword) the unconditional probability of pword to occur. The PMI is thus the measure of statistical dependence of the two, with PMI=0 implying that they are statistically independent. The information retrieval (IR) part of the algorithm requires obtaining these probabilities by counting the total number of co-occurrences. The same is done for words which are identified to have a negative connotation (nword) with regard to a particular phrase. This yields the semantic orientation (SO) of a phrase as

$$
S O(\text { phrase })=\log \left[\frac{\text { hits }(\text { phrase NEAR pword }) * \operatorname{hits}(\text { nword })}{\text { hits }(\text { pword }) * \text { hits }(\text { phrase NEAR nword })}\right]
$$

\footnotetext{
${ }^{11}$ I use the terms reputation and credibility interchangeably throughout the paper, although strictly speaking these two may be distinct. For instance, the G7 may receive a poor assessment in the media, but may still enjoy a high degree of credibility. In the long-run, however, the credibility of an institution should be reflected in its public reputation and the media coverage it receives.

${ }^{12}$ The methodology is described in detail in Hatzvassiloglou and McKeown (1997), Turney and Littman (2001) and Turney (2002). It is a relatively novel approach in economics, though some exceptions are Lucca and Trebbi (2008), who use it to classify FOMC statements into hawkish versus dovish, and in Tetlock (2007) and Tetlock et al. (2008), who employ it to test whether the media coverage of firms helps predict stock returns and trading volumes.
} 
Turney (2001) has shown that using a NEAR operator performs better than using an AND operator, i.e. the semantic orientation of a phrase matches more closely the "true" normative assessment when restricting the proximity to the phrase to a neighborhood of 10 words. ${ }^{13}$

I use the following procedure in applying this methodology to the G7. My focus is on the print media (newspaper articles, newswire reports etc.), using the source Factiva to construct the SO for the G7. I use Factiva for two reasons; first, because of the possibility to have a history of a very comprehensive set of news media reports going back to the 1970s; ${ }^{14}$ and second, because of its stronger inclusion and focus on newswire reports, which are a key source of information for financial market participants.

To identify articles for the G7, I use the search commands ("Group of Seven or G7 or Group of 7") together with ("exchange rate or currency or US dollar or yen or deutsche mark or euro") in order to limit the search to articles that discuss the G7 in connection with exchange rates. Following Turney (2002) and Tong (2001), I use the following set of terms to identify words with a positive connotation (good, excellent, positive, convincing, successful, committed, tough) and those with a negative connotation (bad, poor, negative, unconvincing, unsuccessful, uncommitted, ineffective). The advantage of this choice is twofold; first, in that the terms are mostly direct opposites; and second, that they are relatively uncontroversial in having a positive or negative connotation for this purpose. The SO score for the G7 proved quite robust to using a broader or a narrower set of pwords and nwords.

The co-occurrence of these pwords and nwords with G7 is restricted with a NEAR10 operator to a neighborhood of 10 words. Finally, the semantic orientation for the G7 is estimated for the two-month time period before each G7 meeting ("Pre-G7"), and for the two-month period after each G7 meeting ("Post-G7"). Table 2 gives the total number of hits for the different categories. Overall, there are about 169,000 articles on the G7 and exchange rates around the 76 G7 meetings since 1975 in Factiva. Given the restricted number of pwords and nwords and the NEAR10 restriction, 3170 of these articles have an association of G7 with at least one pword, and about 1500 with at least one nword. The sample split shows that there is a significant increase in coverage after G7 meetings as compared to before.

Table 2 and Figure 2

Based on these raw data, Figure 2 shows the evolution of the semantic orientation of the G7 since 1975, with Panel A showing the overall SO around each meeting (two month before to two months afterwards), while Panel B plots the SO separately for the period before versus the period after each meeting. This proxy of G7 reputation shows some interesting yet

\footnotetext{
${ }^{13}$ Such an assessment of the accuracy in linguistics has been conducted e.g. by comparing the SO of the written text of movie reviews with the overall recommendation of the reviewer ("thumbs up" or "thumbs down"). There is a match between both when the SO score of the text matches the respective recommendation (see Turney 2001).

${ }^{14}$ The coverage of Factiva is relatively thinner in earlier years, in particular before 1985 . However, given the definition of semantic orientation in (6) this is not a problem as the measure corrects for the unconditional frequency of pwords and nwords.
} 
intuitive changes over time: the G7 appears to have enjoyed a lot of positive media coverage in the second half of the 1980s, following the Plaza and Louvre Accords, as well as in the second half of the 1990s. By contrast, the semantic orientation of the G7 was relatively negative in the early period as well as in the early 2000 s.

The empirical analysis below will test how the semantic orientation of the G7 may have influenced the probability of G7 success in moving exchange rates in the desired direction using the pre-meeting $\mathrm{SO}$ in order to allow for the possibility that success also influences reputation - as well as investigating what factors determine $\mathrm{G} 7$ reputation.

\subsection{Consensus, cacophony and communication across G3 policy-makers}

The final part of this section outlines the measurement and classification of statements of individual G3 policy-makers around G7 meetings. Including the communication of G3 policy-makers is important for understanding both whether G7 meetings succeed in forming consensus and reducing cacophony in communication, and whether this consensus and the intensity of communication are determinants for the success of G7 communiqués.

The objective is to obtain two measures for the communication of individual G3 policymakers. The first one is the intensity of G3 communication after G7 meetings as a proxy for the information content and impact of such communication. The second it the degree of disagreement or cacophony with which G3 policy-makers speak in order to measure the clarity and consensus among these policy-makers. The extraction and classification of G3 communication is not an original contribution of the present paper, but has largely been done in Fratzscher $(2004,2008)$ and Fratzscher and Mehl (2008), with the only addition that the data has been extended backwards, to the extent possible, to 1975. A detailed description of the methodology is presented in Appendix A.

The empirical analysis below will test whether the degree of G3 consensus has been affected by the G7 meetings themselves, and also to what extent higher G3 consensus and lower communication cacophony may contribute in explaining the success of G7 interventions in moving exchange rates in the desired direction.

\section{How much Success for the G7?}

I now turn to the empirical assessment of the G7, starting by outlining a sketch of a model to illustrate the functioning of the coordination channel (section 3.1). I then turn to the empirical results; first analyzing to what extent G7 meetings have been successful in moving exchange rates in the desired direction (section 3.2), and then asking what factors may help explain when and under what circumstances the G7 is successful (section 3.3). 


\subsection{The functioning of the coordination channel}

A fundamental issue is why G7 communication should have any effect on exchange rates at all. An important recent strand of the exchange rate literature argues that exchange rates may not be distinguishable from a random walk because currency movements occur mainly due to changes in expectations about future fundamentals (Engel, Mark and West 2007; Engel and West 2006). But at least part of the information of G7 communiqués may be anticipated by financial markets. The answer is that policy interventions or important statements, such as G7 communiqués, may not contain new information, yet may still affect FX markets through what Sarno and Taylor (2001) coined a coordination channel. The essence of the argument is that a coordination failure among market participants may induce currency values to deviate from underlying economic fundamentals, and policy statements may function as a device to coordinate beliefs and make currency values revert back to sustainable levels.

To provide a brief, stylized illustration of the functioning of the coordination channel, asset prices and the exchange rate can be modeled in an asset-pricing framework, where the log exchange rate $s_{t}$ is the discounted value of private agents' expectations (with discount factor $\phi$ ) about future fundamentals $f_{t+i}$ :

$$
s_{t}=\boldsymbol{C}-\phi \sum_{i=0}^{\infty} \phi^{i} E_{t}\left(f_{t+i} \mid \Omega_{t}\right)
$$

with $\Omega_{t}$ as the public information available to agents at time t. It is useful to formulate a dynamic specification and to split this information set into a known component about fundamentals - such as the interest rate differentials between the home economy and the rest of the world $\left(i-i^{*}\right)$ and a risk premium $\rho$ as in a standard UIP relationship - and an unknown component which agents need to anticipate:

$$
\Delta s_{t+1}=\left(-i_{t}^{*}+\rho\right)+\left(-\phi \sum_{i=0}^{\infty} \phi^{i} \mathbf{E}_{t+1}^{m}\left(f_{t+1+i} \mid \Omega_{t+1}\right)-E_{t}^{m}\left(f_{t+1+i} \mid \Omega_{t}\right)_{-}^{-}\right.
$$

where $E^{m}$ are the expectations of the various individual market participants. This simple formulation helps illustrate how communication may function through a coordination channel, which builds on micro-based models along the lines of the influential work by Evans and Lyons (2002). The main premise of these microstructure models is that information is not common knowledge but differs among agents. Private information about fundamentals becomes public and is shared by participants through the trading process. In essence, it is this heterogeneity of information which enables the functioning of the coordination channel.

The crucial point of equation (8) is that policy communication or policy action may influence exchange rates not only by providing new information, but merely by inducing agents to revise and coordinate their expectations. There is indeed evidence that such a coordination channel is at work in FX markets (e.g. Taylor 2004, and Fratzscher 2008). Applied to G7 
communication, such statements may not contain any new information, but may coordinate trading decisions by helping opinions about fundamentals to converge, thereby altering the desired portfolio allocations and thus the level of the exchange rate.

\subsection{Perceived success versus actual success}

Turning to the empirical results, the starting point is to identify the success of G7 meetings in moving G3 currencies in the desired direction, using the direction criterion and the reversal criterion of (1) and (2) above, and distinguishing between the "perceived" success - i.e. whether currencies moved relative to a random walk counter-factual - and the "actual" success - i.e. whether they moved in the desired direction relative to the counter-factual from the factor model.

Figure 3

Figure 3.A compares the factual exchange rate evolution (averaged across all three G3 currency pairs) with the one predicted by the factor model. Just as for Figure 1, note that exchange rate changes in this figure are signed, i.e. an increase in an exchange rate after G7 meetings indicates a move in the intended direction, and a decrease is a change in the undesired direction. From the evolution of factual exchange rates, the first impression one gets is that the G7 was an overwhelming success. Not only do all three currency pairs go in the intended direction, but the move becomes ever large over time. However, the predicted exchange rate evolution based on the factor model is strikingly close, implying that G3 exchange rates would have changed in a similar fashion also if no G7 intervention had taken place. Nevertheless, the predicted changes are mostly below the factual changes, so that there does seem to be some effect of the G7 on G3 currencies. Figure 3.B plots this effect, or "actual" success, in the dashed lines (for each G3 currency pair), which is the difference between the factual change and the predicted move, i.e. $r_{t+k}-E_{t}^{F} \boldsymbol{\epsilon}_{+k}$ -

Table 3 and Figure 4

Table 3 provides the formal sign tests, comparing the perceived success with the actual success of G7 communiqués. The difference between both is indeed striking. The direction criterion indicates that the perceived success ratio is quite high, and even rising with the time horizon. There is an impressive $81 \%$ directional perceived success rate 12 months after G7 meetings, implying that G3 currencies have moved in the direction intended by the G7 in more than 4 out of 5 cases.

The actual success ratios paint a very different picture. Not only is the success rate lower when accounting for market factors, but the sign test for the directional criterion is statistically insignificant beyond a one-month horizon. Nevertheless, the actual success rate is statistically significant at horizons of a few days and up to one month. It is, of course, a 
subjective judgment whether one considers a success rate e.g. of $60 \%$ as high or low, though the actual success ratios are mostly persistently higher than 50\% at horizons up to 5-6 months. Figure 4 plots the actual success against the perceived success for two of the currency pairs, the US dollar - euro and the US dollar - yen, underlining the increasing discrepancy between both the longer the time horizon.

How should one interpret these findings? One interpretation is that G7 meetings only have a temporary effect on G3 currencies. Nevertheless, in efficient asset markets in which most new information is incorporated within minutes or a day, identifying an effect of G7 interventions in FX markets still after one month may be considered quite impressive, and may be interpreted as evidence that a coordination channel, outlined by Sarno and Taylor (2001) and others, may indeed be at work. Overall, a fair interpretation of the findings seem to be that the G7 is quite accurate in pointing out currency misalignments and that its communications help accelerate the convergence process of G3 currencies to more sustainable levels.

I conduct various extensions and modifications in order to gauge the robustness of these findings. An important issue is the specification of the factor model to extract counter-factual exchange rate predictions. There are various choices as to the number of factors to be included and the definition of the individual factors. My strategy is to include all four factors and to pick the specification that most closely fits the factual evolution of G3 currencies after G7 meetings. Hence the actual success ratios shown in Table 3 should be considered as constituting a lower bound.

A second robustness check is to extract actual and perceived success ratios for effective exchange rates, rather than bilateral currency pairs. The empirical findings for the success ratios of effective exchange rates, not shown here for brevity reasons, are overall robust and very similar to those shown in Table 3 for the bilateral rates..

Table 4

Moreover, it may be argued that the G7 is not just interested in managing the level of G3 currencies, but that it also attempts to calm markets and reduce volatility and uncertainty. In fact, many G7 statements stress the undesirability of "excessive" currency movements or "volatility". Table 4 shows the directional success ratios for the volatility of bilateral G3 currencies (Panel A) and for the three effective exchange rates (Panel B). I use two proxies, one being the realized volatility (measured as the standard deviation of daily currency changes) $\mathrm{k}$ periods before versus $\mathrm{k}$ periods after G7 meetings, and the second being the difference in the absolute exchange rate changes between $\mathrm{k}$ periods before versus $\mathrm{k}$ periods after G7 meetings.

However, Table 4 indicates that there is no evidence at all that G7 meetings have reduced volatility when using any of these proxies. In fact, the success ratio is in some cases below $50 \%$ and statistically significant, implying that volatility increases after G7 meetings over 
some horizons. This may not be surprising if the true objective of the G7 is to target the level of currencies, as it does seem to do on the day of the release of the G7 statement (1D). ${ }^{15}$

In summary, the evidence presented here suggests that the "perceived" success of G7 meetings has been impressive as G3 currencies move in the desired direction in the great majority of cases of such meetings. However, the findings suggest that this should not necessarily be interpreted as a causal effect of G7 interventions, but at least partly as the result of market forces that induce misaligned currencies to revert back to more sustainable levels. In fact, the "actual" success rate of the G7 is statistically significant only at horizons up to about one month, but not beyond. This suggests that the G7 is not only quite accurate in calling misalignments, but that it also plays a fairly effective role in accelerating this convergence process.

\subsection{Determinants of $\mathrm{G} 7$ success}

What determines whether and when the G7 is successful in managing G3 exchange rates? The evidence above based on the factor model suggests that the G7 is fairly successful overall in moving currencies at shorter horizons of up to a few months, but not beyond. Nevertheless, it is important to emphasize that e.g. a balanced success-failure ratio of $50 \%$ at a five-month horizon (as shown in Table 3) does not necessarily mean that the G7 has no causal effect on G3 currencies at that horizon. It is well possible that certain elements under the control of G7 succeed in moving currencies in the desired direction in some occasions, but have no or the opposite effect in others.

What are such potential determinants? As a first set of determinants, the literature on communication and the ability of policy-makers in managing expectations, as mentioned in the Introduction, stresses the importance of clarity and transparency for the success of communication. In particular, many studies (e.g. Blinder 2001) stress that cacophony in communication is harmful to the ability to manage expectations and move financial markets in the desired direction. For the G7, I use the various proxies described in section 2 to quantify the clarity of G7 communication. A first element is the degree of cacophony after G7 meetings. One would expect that greater consensus across G3 policy-makers, and with the G7 statement, in the weeks and months after G7 meetings should help markets understand the intentions and make the impact of the G7 message stronger.

A second proxy is the intensity of G3 communication after G7 meetings, which may also be beneficial. However, the impact of communication may very much depend on the attention it gets in the media. A third determinant may therefore be the intensity of media coverage of the G7 after meetings. Finally, the G7 message may matter itself, as e.g. a change and clear break with past language may draw more attention and have a bigger market impact.

\footnotetext{
${ }^{15}$ The use of unconditional volatilities, of course, makes this finding not unexpected. An ARCH-type modelling would be more appropriate to condition on level changes and to extract conditional variances, if this was the true objective of the G7.
} 
As a second category, it may not just be the clarity of communication, but also the overall reputation and credibility that the $\mathrm{G} 7$ enjoys with the public and market participants. A caveat is that G7 reputation may itself be endogenous to G7 success or failure. Hence the degree of G7 reputation in the two months before each G7 meeting is included in the analysis as a determinant. As a third category, it is important to take into account the possibility that G3 authorities do not only use communication, but also other policy tools to achieve their objectives. The Plaza Accord discussed above is a case in point, as policy-makers used actual FX interventions to weaken the US dollar. Moreover, another policy tool is monetary policy, which may be used to influence currencies, in addition or apart from communication.

As a fourth and final set of controls, it is relevant to control for market factors that may influence currency values. For instance, G7 interventions may be more effective in an environment of large market volatility, and when exchange rates are strongly misaligned. Note that the actual success rate used to measure G7 success already takes into account the likely effect of such market factors on exchange rates. However, it is possible that also communication has a larger effect under such a market environment (e.g. Fratzscher 2008). Tables A.1-2 provide summary statistics and cross-correlations for all these determinants.

Table 5

Table 5 shows the estimates for these different determinants of the actual success of G7 communiqués, over a one-month horizon, using a logit specification for the three G3 currency pairs combined. ${ }^{16}$ Overall, G7 reputation seems to have a significant and sizeable effect on the probability of G7 success. Similarly, a higher consensus (lower cacophony) among G3 policy-makers is important in raising the likelihood of G7 success, as is the intensity of the media coverage, i.e. the ability of the G7 to reach the public. However, neither the communication intensity/frequency nor a change in the $\mathrm{G} 7$ communiqué appear to exert a significant effect on the probability of G7 success.

Moreover, the success of the G7 in managing G3 exchange rates is also influenced by other policy choices. In particular, G7 statements that were supported through actual FX interventions are significantly more successful. ${ }^{17}$ Monetary policy - measured as the shortterm (money market) interest rate differentials - does not appear to be significant, also when using other proxies such as the direction of relative policy rates. However, an important caveat is that it is difficult to measure changes in market expectations about monetary policy that may have been triggered subsequent to G7 meetings, and in particular since 1975, so that

\footnotetext{
${ }^{16}$ I take the "actual success" measure as the dependent variable, rather than the "perceived success", in order to be as cautious and conservative as possible about the G7 success ratio. However, the findings about the determinants for the "perceived success" are qualitatively very similar to those for the actual success of the G7 presented in this section.

${ }^{17}$ The actual intervention variable is a dummy with a value of one if at least one G3 authority intervened against another G3 currency subsequent to a G7 meeting, and zero otherwise. US and German interventions are available from the late 1970s onwards, but for Japan such data is public only since 1991, so that this intervention variable may not be entirely accurate for this earlier period.
} 
one should treat this finding with caution. Finally, also market conditions seem to matter, as G7 statements tend to be more successful when currency misalignments are large.

Figure 5

Figure 5 provides illustrations about the size of the effect of these different determinants. Splitting each determinant into high and low values relative to the sample average, Panel A shows that the effect of G7 reputation on G7 success is indeed very substantial. The G7 success rate at short horizons of a few weeks is a remarkable $80 \%$, and still $65 \%$ after 4 months, before gradually falling and converging to the same success rate as for those G7 meetings when the G7 had a low degree of reputation. G7 meetings with a low G7 reputation are mostly associated with a success rate of less than 50\%, and in some cases statistically significantly so.

A similar picture applies to G7 consensus, shown in Panel B, although the difference is less sizeable than for G7 reputation. Finally, G7 meetings that receive a lot of media attention tend to also be much more likely to be successful. As for the other two determinants, this difference declines over time and becomes insignificant at longer horizons close to one year.

Table 6

I conduct various robustness checks of the results. Table 6 indicates that the findings are robust when including not only bilateral but also effective G3 exchange rates (columns (1)). The other two sets of columns in Table 6 repeat the analysis of Table 5 for horizons of 2 weeks and 3 months after G7 meetings. The estimates are similar in magnitude but statistically more significant at shorter horizons, such as 2 weeks, but become less significant the longer the time horizon. At the 3-month horizon of (3), only G7 reputation and G3 consensus remain statistically significant, and at horizons beyond that none of the determinants is significant any longer. Again, this is very consistent with the findings above that showed that the G7 has only a temporary effect on G3 currencies of up to a few months, but not beyond.

Overall, the findings of this sub-section underline two points. First, the actual success of the G7 in managing G3 currencies, as identified in the previous sub-section, is not a statistical fluke. If the identified G7 success was e.g. merely the result of omitted variables, then none of the determinants identified in this sub-section should exert a significant effect on the likelihood of G7 success. The second point is that G7 reputation and G3 consensus (in addition to actual interventions) have a significant and sizeable effect on G7 success. This suggests that success is not only the result of market factors over which policy-makers have less influence, but that it is to a considerable extent endogenous to G3 policy-makers themselves. This is the issue I turn to next. 


\section{The Role of Reputation and Consensus}

The reputation of the G7 as well as the ability of G3 policy-makers to communicate clearly and with a consensus have been identified as two key elements for explaining when and under what circumstances the $\mathrm{G} 7$ has been successful in managing exchange rates. But what determines reputation and consensus, and how can these be built and maintained in order for the $\mathrm{G} 7$ to be effective?

Tables $7-8$

Turning first to G3 consensus, Table 7 shows that the degree of consensus across all G3 policy-makers appears to have increased significantly, on average, in the two months following G7 meetings as compared to before G7 meetings. With the measure of G3 consensus lying between 0 and 1, the average consensus over the sample period 1975-2008 before G7 meetings was 0.44 , but rose to 0.62 after G7 meetings. The last column of Table 7 shows that this difference is statistically significant. An intriguing picture emerges when splitting the sample, which indicates that this increase in G3 consensus is almost entirely due to the period 1975-1995. From 1996 onwards (bottom row of Table 7), the degree of consensus was on average not only lower than after G7 meetings before 1996, but it was also not significantly higher than in the months before G7 meetings. Overall, this suggests that the G7 has not been as effective in forming a consensus among its members over the past decade.

What explains G3 consensus? This question is hard to answer as there may be a multitude of factors that influence whether or not G3 policy-makers agree, and in particular whether they stick to a consensus in their individual communications on exchange rates after $\mathrm{G} 7$ meetings. Table 8 indicates that market factors, such as the degree of currency misalignments or volatility, have no correlation with G3 consensus, as does the G3 monetary policy stance. There is only some evidence that G3 consensus is higher when G3 policy-makers conduct actual interventions, though this effect is statistically significant only for the larger G7 sample that includes all $76 \mathrm{G} 7$ meetings.

It thus appears hard to say what precisely determines the degree of cacophony and consensus in the way G3 policy-makers communicate - and political economy factors, which are not addressed here, may be a big part of it - though Table 7 nevertheless indicates that G7 meetings in general have been reasonably effective in forming a consensus.

\section{Table 9}

Turning to the second focus, the previous section has underlined the importance of G7 reputation as a key factor in managing exchange rates. Can G7 members build and maintain the reputation and credibility of the G7, not just for its own sake, but to ensure an important pre-condition for its effectiveness? A first and obvious point is that G7 reputation should be positively affected by its success in managing exchange rates. 
Using G7 reputation in the post-G7 period as the dependent variable, column (1) of Table 9 shows that there is indeed a strong positive relation between G7 success and G7 reputation. What is intriguing is that it is not only the actual success, but also the perceived success that has a positive relation with $\mathrm{G} 7$ reputation. ${ }^{18}$ This is an interesting finding because it suggests that the $\mathrm{G} 7$ benefits in terms of reputation from speaking out about exchange rates, even if it has no causal effect in moving G3 currencies.

Model (2) in Table 9 shows the relation of the various determinants of success, as identified in Tables 4 and 5, and G7 reputation. Both the degree of media coverage as well as the intensity of G3 communication are positively associated with G7 reputation. Interesting is also the finding that $\mathrm{G} 7$ reputation is highly persistent over time, which is indicated by the sizeable point estimate on $\mathrm{G} 7$ reputation before $\mathrm{G} 7$ meetings.

Model (3) of Table 9 extends the analysis to all 76 G7 meetings, i.e. including not only those in which the G7 issued a statement on exchange rate levels, but also those meetings where it issued a general statement on exchange rates without providing guidance on bilateral G3 currencies. The interesting finding of that model is the negative and significant coefficient on the variable "G7 no focus dummy", which is a dummy for those G7 meetings when the G7 did not provide guidance about its views and intentions on G3 currencies. It suggests that G7 reputation and credibility benefit from the G7 speaking out about currency levels, and not doing so diminishes the G7's standing.

To sum up, the success of the G7 in managing exchange rates depends on factors that are endogenous to the policy-making process itself, and in particular to factors such as the reputation of the G7 and its ability to form a consensus and speak with one voice to the public. The evidence suggests that G7 reputation is persistent and built gradually, and importantly, that speaking out about and guiding markets about exchange rates tends both to be successful and to help enhance the G7's reputation and credibility. Moreover, there is evidence that G7 meetings themselves have been fairly effective in building consensus among its members, though this effect seems to have waned over the past decade.

\section{Conclusions}

The objective of the paper has been to assess the extent to which the G7 has been successful in managing G3 exchange rates since the 1970s. The difficulty of such an assessment is to gauge the counter-factual, i.e. how G3 currencies would have evolved if G7 communiqués and coordinated policy action had not occurred. If one looks at factual G3 currency movements after G7 meetings, G3 currencies have moved in the direction intended by the G7 in as many as $80 \%$ of the cases over the subsequent 12 months. Thus if one takes this factual evolution (i.e. a random walk) as the counterfactual, it is tempting to conclude that the $\mathrm{G} 7 \mathrm{has}$

\footnotetext{
${ }^{18}$ The dummy variable for perceived success in the table captures only those post-G7 periods in which G3 exchange rates were found in Table 3 to be a perceived success, but not an actual success.
} 
been highly successful. However, G7 communiqués have often been most outspoken when exchange rates were highly misaligned and in periods of large market uncertainty. Using a factor model that takes into account misalignments and market conditions at the time of G7 meetings indicates that the G7 has been effective in moving G3 currencies in the desired direction only at horizons of up to three months, but not beyond. Even if one believes in the validity of such a more conservative counter-factual, the evidence nevertheless suggests that the G7 has been fairly effective and has played an influential role in helping accelerate the convergence process of currencies back to more sustainable levels over the course of several weeks and months.

While the success of the G7 in managing exchange rates is partly dependent on the market environment - such as the degree of existing currency misalignments - it is also to a significant degree endogenous to the policy process itself. The paper shows that the reputation and credibility of the G7 as well as the clarity and consensus in its communication are important determinants for the G7's ability to manage G3 currencies. Equally importantly, being explicit and speaking out in the past about G3 currencies and misalignments has proven to be beneficial for the reputation of the G7, whereas G7 reputation has tended to suffer when the $\mathrm{G} 7$ abstained from providing guidance on $\mathrm{G} 3$ exchange rates.

The motivation for this study of the G7 clearly stems from the larger policy question of how international policy coordination is and should be conducted. The findings of the paper underline the importance of the G7, but also its limitations in managing exchange rate configurations. As for any empirical analysis and assessment, its approach and focus have been backward-looking. Yet the question currently widely debated is what the future of the G7, and more generally of global economic governance should be.

Another dimension is that (inevitable, given the history of the G7) the focus of the paper has been on G3 currencies, while much of the emphasis of the G7 since 2004 has been on encouraging exchange rate flexibility and appreciation of emerging market currencies, in particular that of the Chinese renminbi. It will be important to understand what role the G7 has played in this regard, and how it will manage to deal with emerging global players in the future.

Moreover, multilateral institutions, like the IMF, have implemented reforms for a better monitoring of currency policies in recent years, such as through the landmark framework on IMF bilateral surveillance in June 2007 that commits its members to a code of conduct on domestic and exchange rate policies. However, the evidence of the paper suggests that the G7 has been a fairly effective policy institution in the past. Also given the importance of its members, this may call for the G7 to continue to play a central role in the management of global currency issues, though the challenge will be how emerging markets and multilateral institutions can be made to share responsibility more effectively in the future. 


\section{References}

Barro, R., and Lee, J.W., 2005. IMF Programs: Who Is Chosen and What Are the Effects? Journal of Monetary Economics, Vol. 52, No. 7, 1245-1269

Beine, Michel, Gust Janssen, and Christelle Lecourt. 2006. Should Central Bankers Talk to the FX Market? Unpublished, available at http://homepages.ulb.ac.be/ mbeine/

Bernanke, Ben S. 2004. Fedspeak. Address to the American Economic Association meetings, San Diego, 3 January 2004.

Bergsten, C. Fred and Randall Henning, 1996. Global Economic Leadership and the Group of Seven, Institute for International Economics, Washington D.C,

Blinder, Alan S. 2004. The Quiet Revolution: Central Banking Goes Modern. New Haven, $\mathrm{CN}$ : Yale University Press.

Blinder, Alan, Michael Ehrmann, Marcel Fratzscher, Jakob de Haan, David-Jan Jansen, 2008. Central bank communication and monetary policy: A survey of the evidence, NBER Working Paper No. 13932, forthcoming Journal of Economic Literature.

Boughton, James, 2001. Silent revolution - The international monetary fund 1979-1989, http://www.imf.org/external/pubs/ft/history/2001/index.htm

Cheung, Y, M. Chinn and A. Garcia Pascual. 2005. Empirical Exchange Rate Models of the 1990's: Are Any Fit to Survive?, Journal of International Money and Finance 24 (2005), 1150-1175.

Clarida, Richard and Daniel Waldman, 2007. Is Bad News About Inflation Good News for the Exchange Rate? NBER Working Paper No. 13010, April 2007.

Dominguez, Kathryn M. and Jeffrey A. Frankel. 1993. Does Foreign Exchange Intervention Matter? The Portfolio Effect, American Economic Review 83:5, 1356-69.

Dreher, A., Marchesi, S., Vreeland, J.R., 2007, The Politics of IMF Forecasts. KOF WP 176.

Ehrmann, Michael, and Marcel Fratzscher. 2007. Communication by Central Bank Committee Members: Different Strategies, Same Effectiveness? Journal of Money, Credit, and Banking, 39(2-3): 509-41.

Engel, Charles and Kenneth West, 2006. Exchange Rates and Fundamentals, Journal of Political Economy 113, 485-517.

Engel, Charles, Nelson Mark and Kenneth West, 2007. Exchange Rate Models Are Not as Bad as You Think, NBER Macroeconomics Annual.

Evans, Martin D.D. and Richard Lyons, 2002. Order Flow and Exchange Rate Dynamics, Journal of Political Economy, 170-180.

Fatum, R. and Hutchison, M. (2003). Is Sterilised Foreign Exchange Intervention Effective After All? An Event Study Approach, Economic Journal, vol. 113(April), pp. 390-411.

Fratzscher, Marcel. 2004. Communication and Exchange Rate Policy, ECB Working Paper 363, forthcoming Journal of Macroeconomics. 
Fratzscher, Marcel. 2008. Oral Interventions versus Actual Interventions in FX Markets-An Event-Study Approach, Economic Journal July 2008.

Fratzscher, Marcel and Arnaud Mehl, 2008. Do China and oil exporters influence major currency configurations?, mimeo, June 2008.

Funabashi, Yoichi. 1988. Managing the Dollar: From the Plaza to the Louvre. Washington, D. C.: Institute for International Economics, 1988.

Hatzivassiloglou, Vasileios and Kathleen R.. McKeown (1997): Predicting the semantic orientation of adjectives, Proceedings of the 35th Annual Meeting of the ACL and the 8th Conference of the European Chapter of the ACL, pp. 174-181.

Henning, Randall, 2008. Accountability and Oversight of US Exchange Rate Policy, Peterson Institute for International Economics, Washington D.C,

Holsti, O. (1969). Content Analysis for Social Sciences and Humanities. Addison-Wesley.

Humpage, O. (1999). US Intervention: Assessing the Probability of Success, Journal of Money, Credit and Banking, vol. 31, pp. 732-47.

Ito, Takatoshi. 2002. Is Foreign Exchange Intervention Effective? The Japanese Experience in the 1990s. NBER Working Paper No. 8914, April 2002.

Jansen, David-Jan, and Jakob De Haan. 2005. Talking Heads: The Effects of ECB Statements on the Euro-Dollar Exchange Rate. Journal of International Money and Finance, 24(2): 343-361.

Jeanne, Olivier, and Jeromin Zettelmeyer, 2001, International Bailouts, Moral Hazard, and Conditionality, Economic Policy, Vol. 33 (October), pp. 409-432.

Jurgensen, Philippe, 1993. Report of the Working Group on Exchange Market Intervention, Washington D.C, U.S. Treasury Department.

Kaminsky, G. and Lewis, K. (1996). 'Does Foreign Exchange Intervention Signal Future Monetary Policy?', Journal of Monetary Economics 37(2), 285-312.

Kearns, J. and Rigobon, R. (2004). 'Identifying the Efficacy of Central Bank Interventions: Evidence from Australia and Japan', Journal of International Economics 66(1), 31-48.

Klein, Michael, Bruce Mizrach, and Robert G. Murphy, 1991. Managing the Dollar: Has the Plaza Agreement Mattered? Journal of Money, Credit, and Banking 23(4), 742-51.

Kuziemko I, Werker E., 2006, How much is a seat on the Security Council worth? Foreign aid and bribery at the United Nations. Journal of Political Economy 114- 905-30.

Lucca, David O. and Francesco Trebbi, (2008). Measuring Central Bank Communication: An Automated Approach with Application to FOMC Statements, mimeo, March 2008.

MacKinlay, A.C. (1997). 'Event Studies in Economics and Finance', Journal of Economic Literature, vol. 35, pp. 13-39.

Mussa, Michael, 1999, Reforming the International Financial Architecture: Limiting Moral Hazard and Containing Real Hazard, in David Gruen and Luke Gower (eds.): Capital Flows and the International Financial System, Reserve Bank of Australia, pp. 216-36. 
Neely, Chris. (1998). 'Technical Analysis and the Profitability of U.S. Foreign Exchange Intervention', Federal Reserve Bank of St. Louis Review, vol. 80(4), pp. 3-17.

Neely, Chris. 2005. An Analysis of Recent Studies of the Effect of Foreign Exchange Intervention, Federal Reserve Bank of St. Louis Review, 87(6), 685-717.

Pojarliev, Momtchil and Richard Levich, 2007. Do Professional Currency Managers Beat the Benchmark?, NBER Working Paper No. 13714, December 2007.

Putnam, Robert and Randall Henning, 1989. The Bonn Summit of 1978: A Case Study in Coordination, In Richard Cooper et al., Can Nations Agree: Issues in International Economic Co-operation, Washington: Brookings Institution.

Rogoff, Ken, 2002, Moral Hazard in IMF Loans. How Big a Concern? Finance and Development, Vol. 39, No. 3.

Rose, Andrew, 2004. Do We Really Know that the WTO Increases Trade? American Economic Review 94(1), March 2004.

Sarno, Lucio and Taylor, Mark (2001). 'Official Intervention in the Foreign Exchange Market: Is it Effective and, If So, How Does it Work?', Journal of Economic Literature 39, 839-868.

Sobel, M. and L. Stedman, 2006. The Evolution of the G7 and Economic Policy Coordination, Department of the Treasury, Occasional Paper no. 3.

Taylor, M. (2004). 'Is official exchange rate intervention effective?', Economica, vol. 71: pp. $1-11$.

Tetlock, Paul (2007): Giving Content to Investor Sentiment: The Role of Media in the Stock Market, Journal of Finance 62(3), 1139-1168.

Tetlock, Paul, Maytal Saar-Tsechansky and Sofus Macskassy, (2008): More Than Words: Quantifying Language to Measure Firms' Fundamentals, Journal of Finance 63(3), 1437-67.

Tong, R.M. (2001). An Operational System for detecting and Tracking Opinions in On-Line Discussions, Working Notes of the ACM SIGIR 2001 Workshop on Operational Text Classification, 1-6, New York, ACM.

Turney, P. D. (2002): Thumbs up or thumbs down? Semantic orientation applied to unsupervised classification of reviews, Proceedings of the 40th Annual Meeting of the Association for Computational Linguistics, pp. 417-424.

Turney, P. D., and M. L. Littman (2002): Unsupervised Learning of Semantic Orientation from a Hundred-Billion-Word Corpus, National Research Council, Institute for Information Technology, Technical Report ERB-1094.

Vitale, P. (1999). 'Sterilized Central Bank Intervention in the Foreign Exchange Market', Journal of International Economics, vol. 49(2), pp. 245-67.

Von Furstenberg, George and Joseph Daniels, 1991. Policy Undertakings by the Seven 'Summit' Countries: Ascertaining the Degree of Compliance, Carnegie-Rochester Conference Series on Public Policy 35: 267-307. 
Woodford, Michael. 2005. Central-Bank Communication and Policy Effectiveness. In The Greenspan Era: Lessons for the Future. Kansas City: Federal Reserve Bank of Kansas City, 399-474. 
Figure 1: Distribution of G3 exchange rate movements around G7 meetings

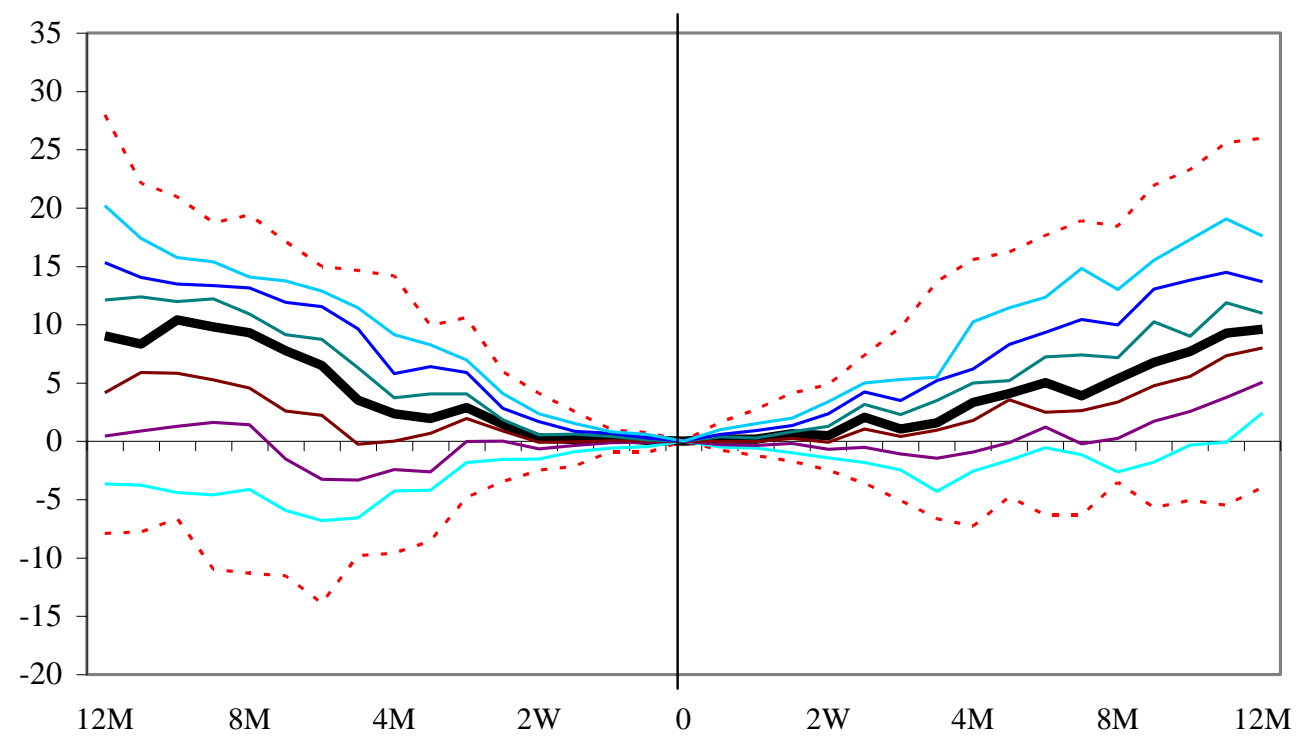

Notes: The figure shows the different deciles of the percentage difference of the three bilateral G3 exchange rate relative to their levels at the day of the G7 meeting (time 0), from 12 months before to 12 months afterwards. G7 meetings are included in the figures only if they give an indication of the desired direction of exchange rate changes. The exchange rate movements, both before and after G7 meetings, are "signed", i.e. a positive change/increase in an exchange rate after G7 meetings shows a move of the respective currency pair in the desired direction. 
Figure 2: Semantic orientation (SO) of G7 media coverage around G7 meetings

\section{A. Overall}

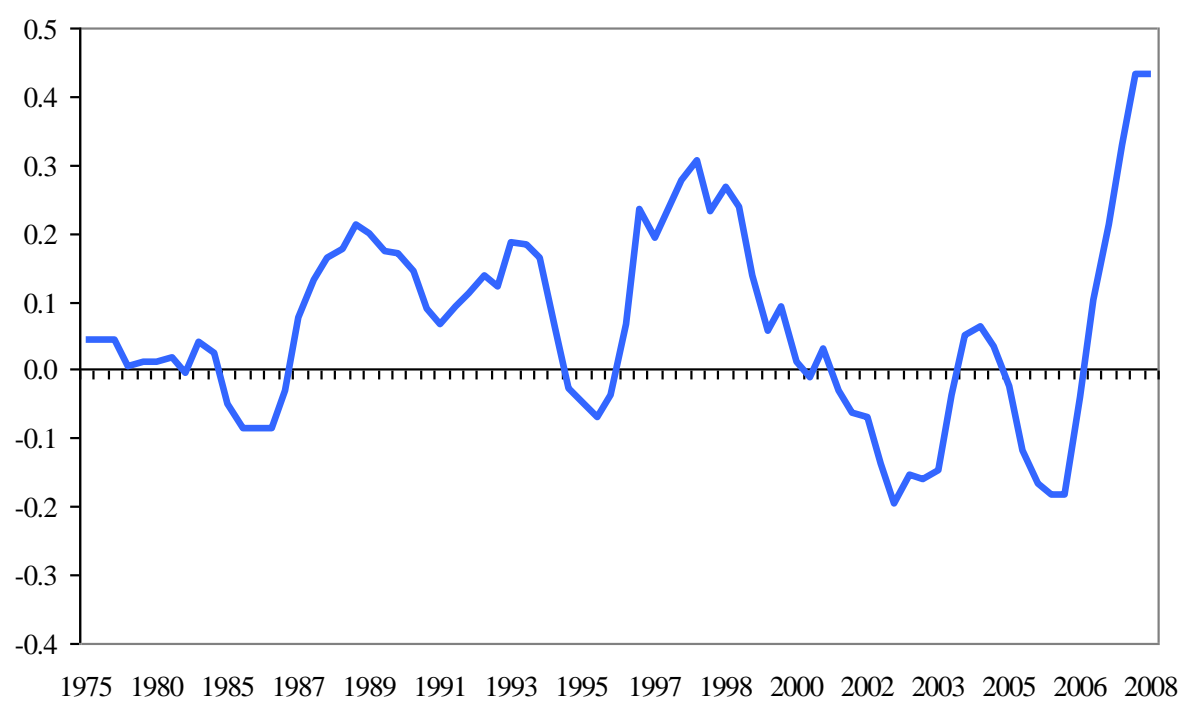

2.B. Before vs. after G7 meetings

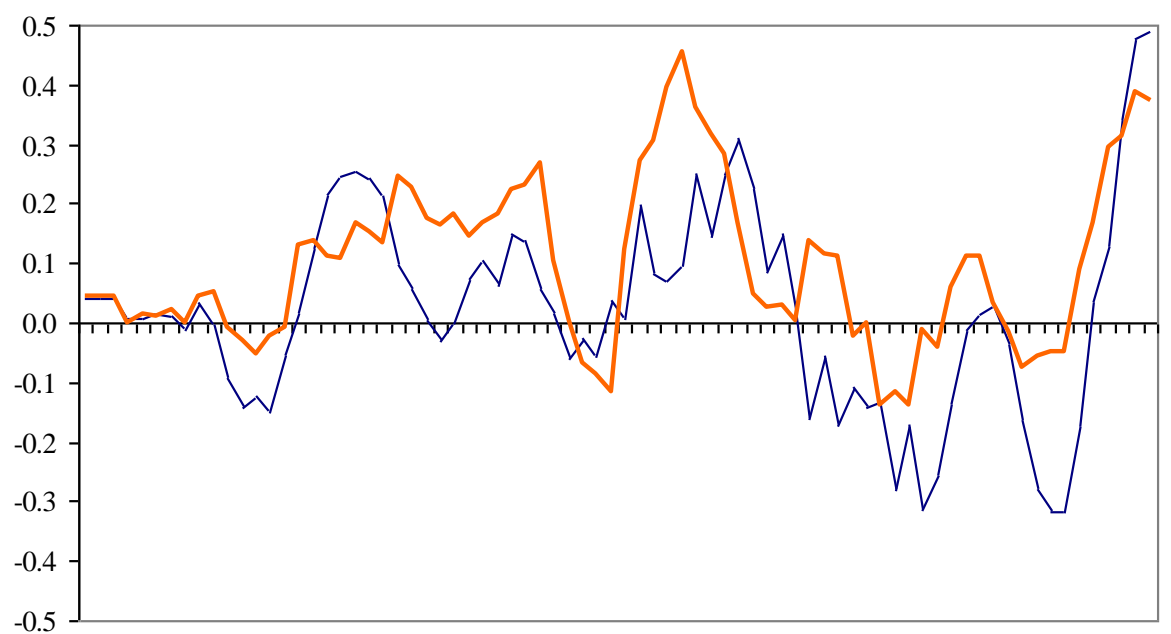

$\begin{array}{llllllllllllllll}1975 & 1980 & 1985 & 1987 & 1989 & 1991 & 1993 & 1995 & 1997 & 1998 & 2000 & 2002 & 2003 & 2005 & 2006 & 2008\end{array}$

$$
\text { — pre G7 meeting _ post G7 meeting }
$$

Notes: Panel A shows the semantic orientation of G7 media coverage during the two months before (pre G7 meeting) and two months after (post G7 meeting) G7 meetings. Panel B shows the split between the periods before versus after G7 meetings. 


\section{Figure 3: Actual success versus perceived success of the G7}

\section{A: Average G3 bilateral exchange rate evolution}

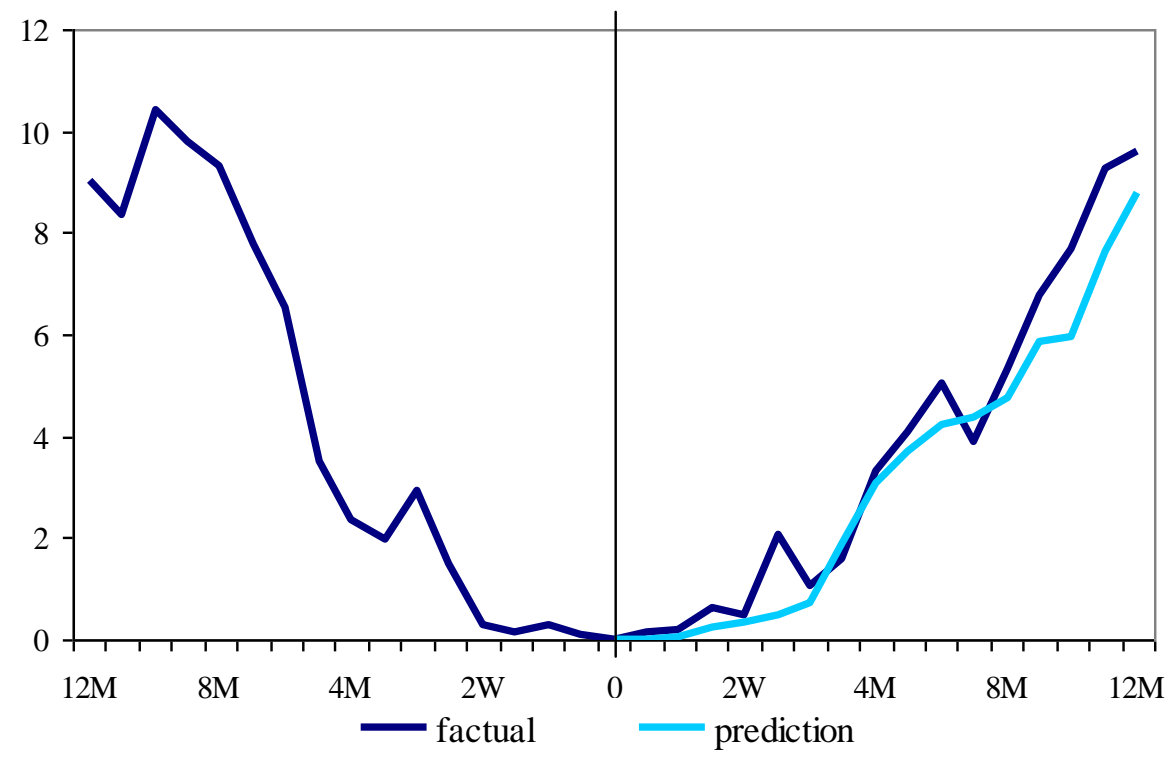

3.B: Individual bilateral exchange rates

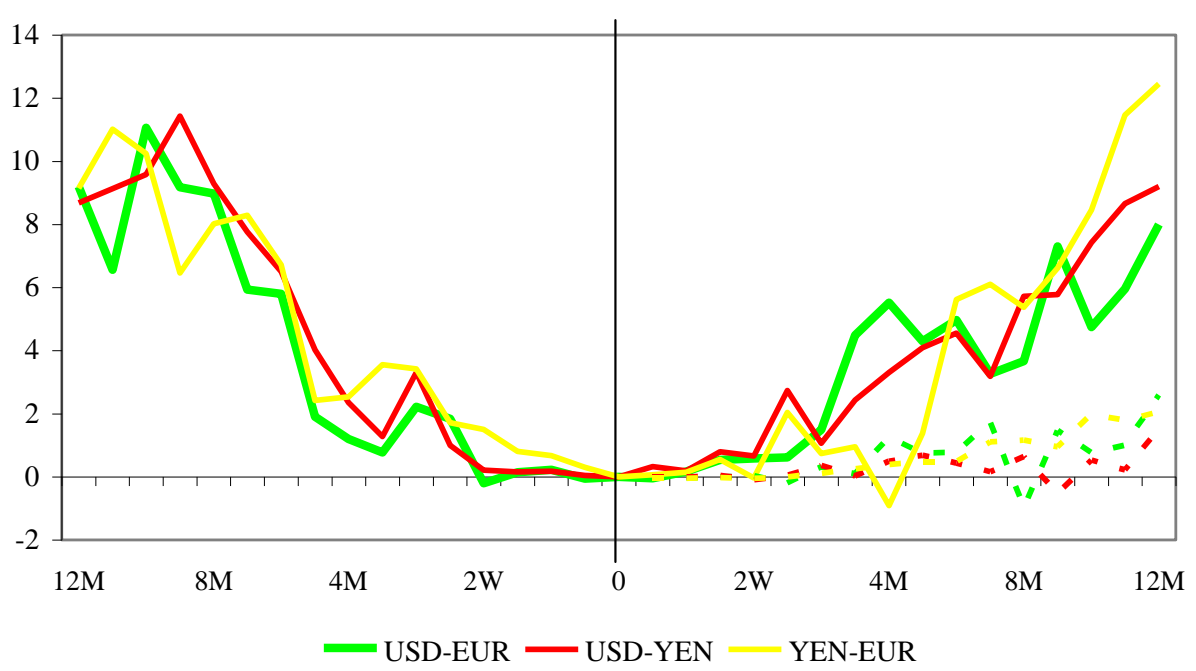

Notes: Panel A shows the average percentage difference of the three bilateral G3 exchange rate relative to their levels at the day of the G7 meeting (time 0 ), from 12 months before to 12 months afterwards. It shows both the factual evolution, as well as the predicted evolution base on the factor model. Panel B breaks down this evolution to the individual G3 currency pairs, with the solid lines after the G7 meetings as the factual exchange rate evolution, and the dashed lines giving the "effective" evolution, measured as the actual evolution minus the predicted evolution based on the factor model, as explained in the text. The G7 meetings included in the figures are only those for which a G7 statement gives an indication of the desired direction of exchange rate changes. The exchange rate movements are "signed", i.e. a positive change/increase in an exchange rate after G7 meetings shows a move of the respective currency pair in the desired direction. 
Figure 4: Success of G7 meetings - bilateral exchange rates

\section{A: USD-EUR bilateral exchange rate}

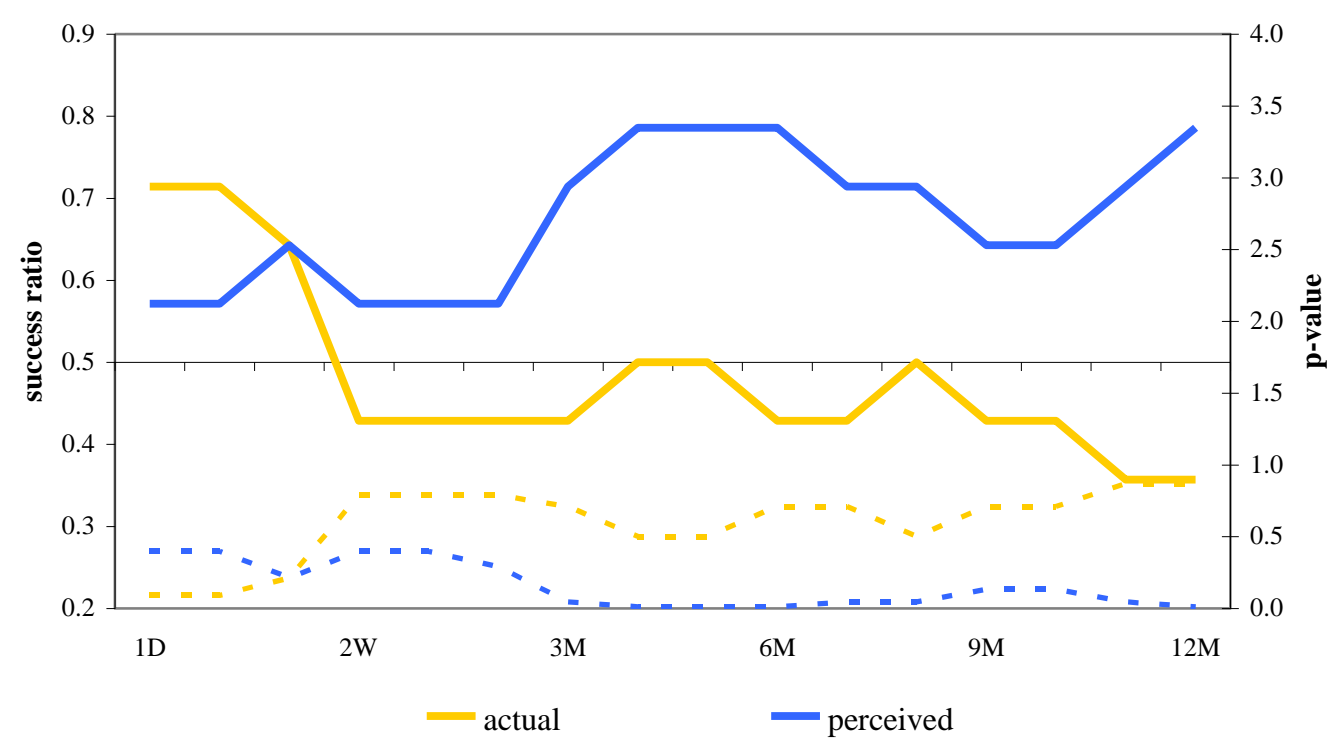

\section{B: USD-YEN bilateral exchange rate}

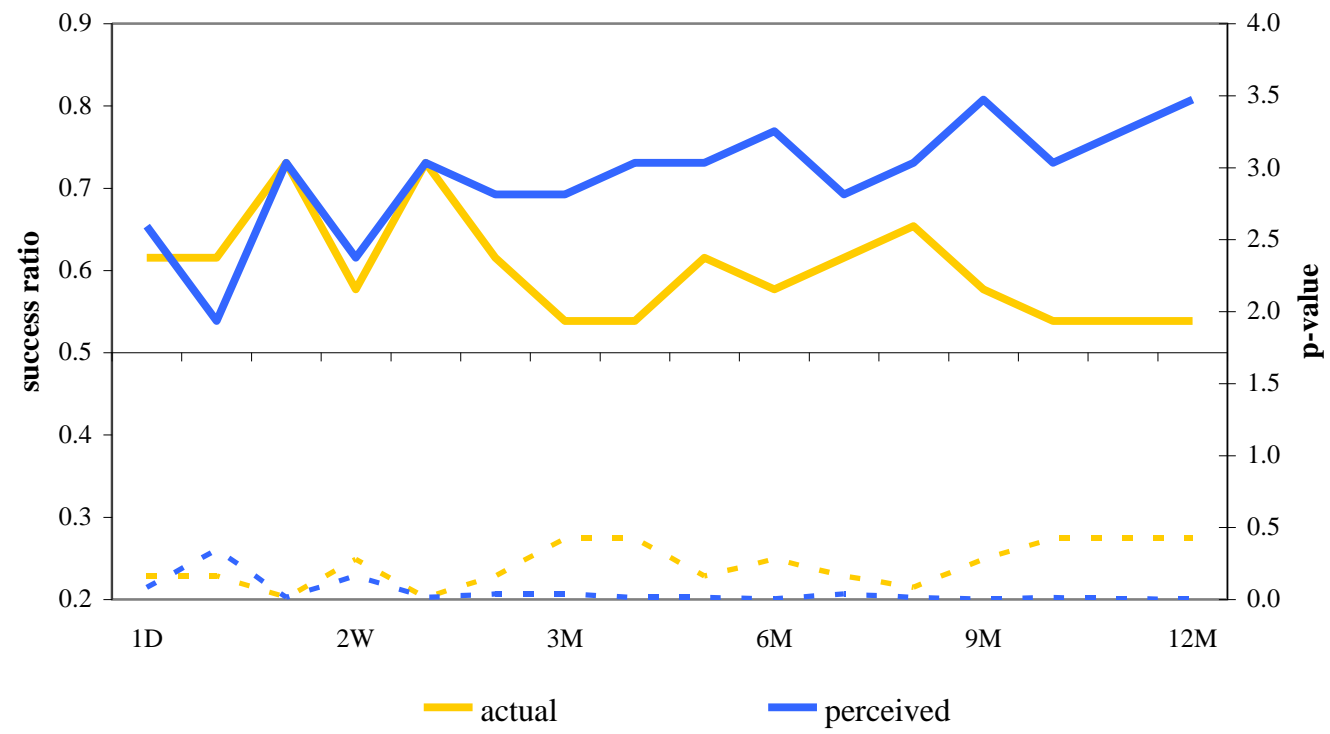

Notes: Panel A for the USD-EUR and Panel B for the USD-YEN bilateral exchange rates show the success ratios of G7 meetings, based on the direction criterion, over various time horizons ranging from 1 day (1D) to 12 months (12M) after G7 meetings. The blue/dark line are the success ratios based on the factual/unadjusted exchange rate changes, while the orange/light line are those based on the adjusted or "effective" exchange rate movements, measured as the factual evolution minus the predicted evolution based on the factor model, as explained in the text. Dashed lines show corresponding $\mathrm{p}$-values for the various success ratios, using the right-hand $\mathrm{y}$ axis. 
Figure 5: Determinants of G7 success

\section{A: G7 reputation / credibility}

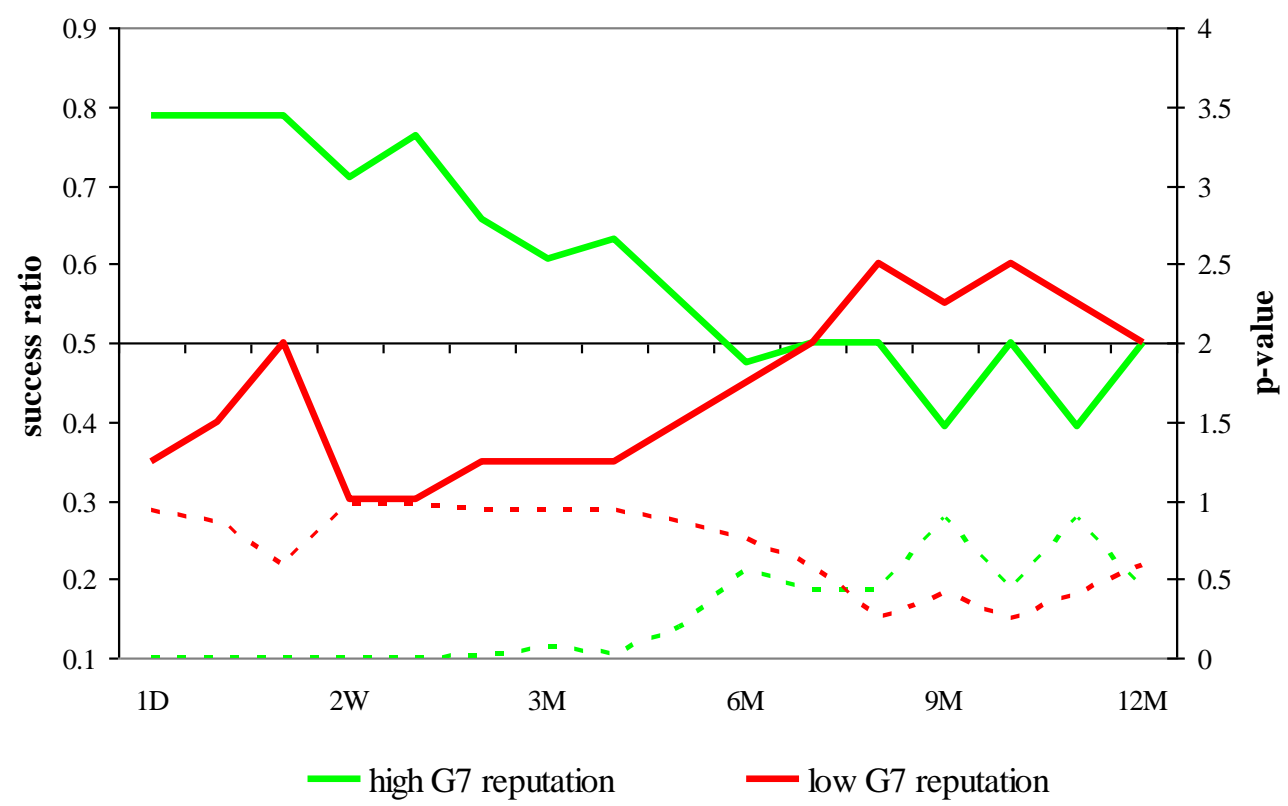

5.B: Consensus among G7 participants

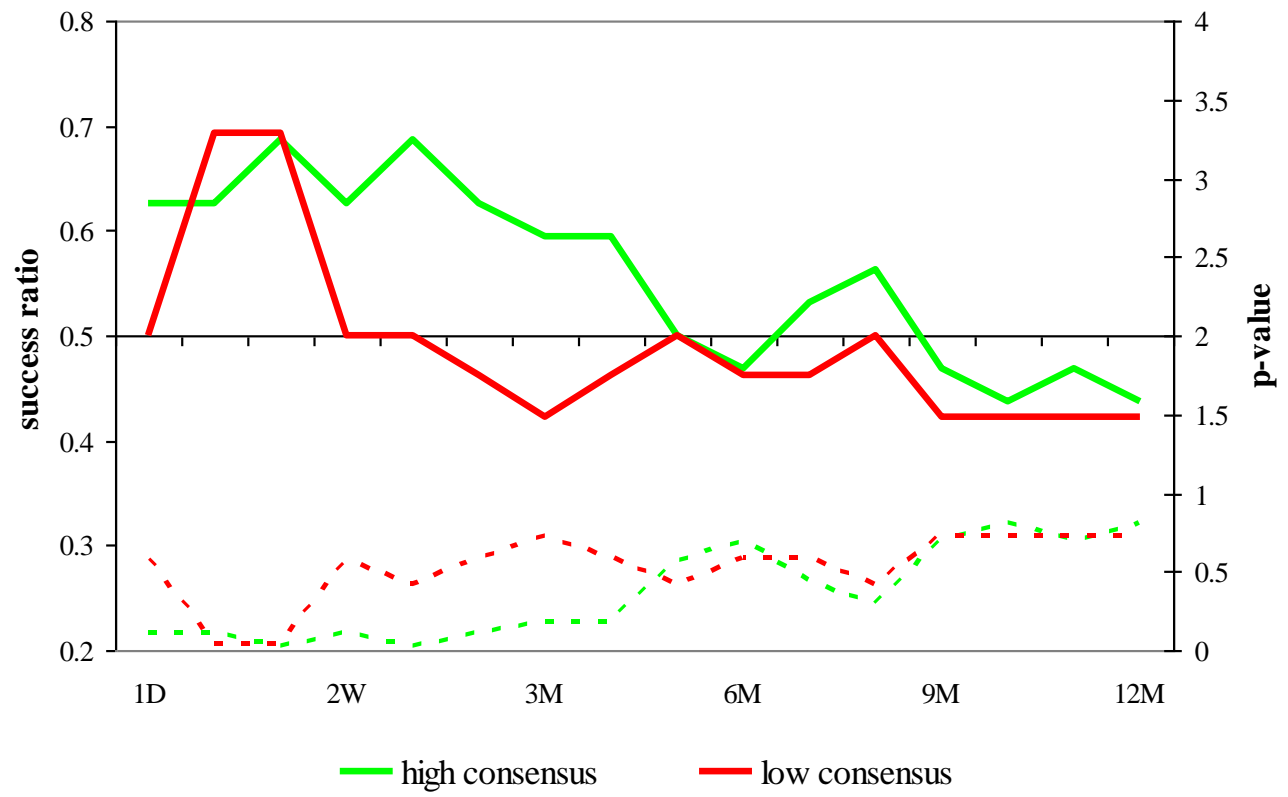

(cont.) 


\section{C: Media coverage}

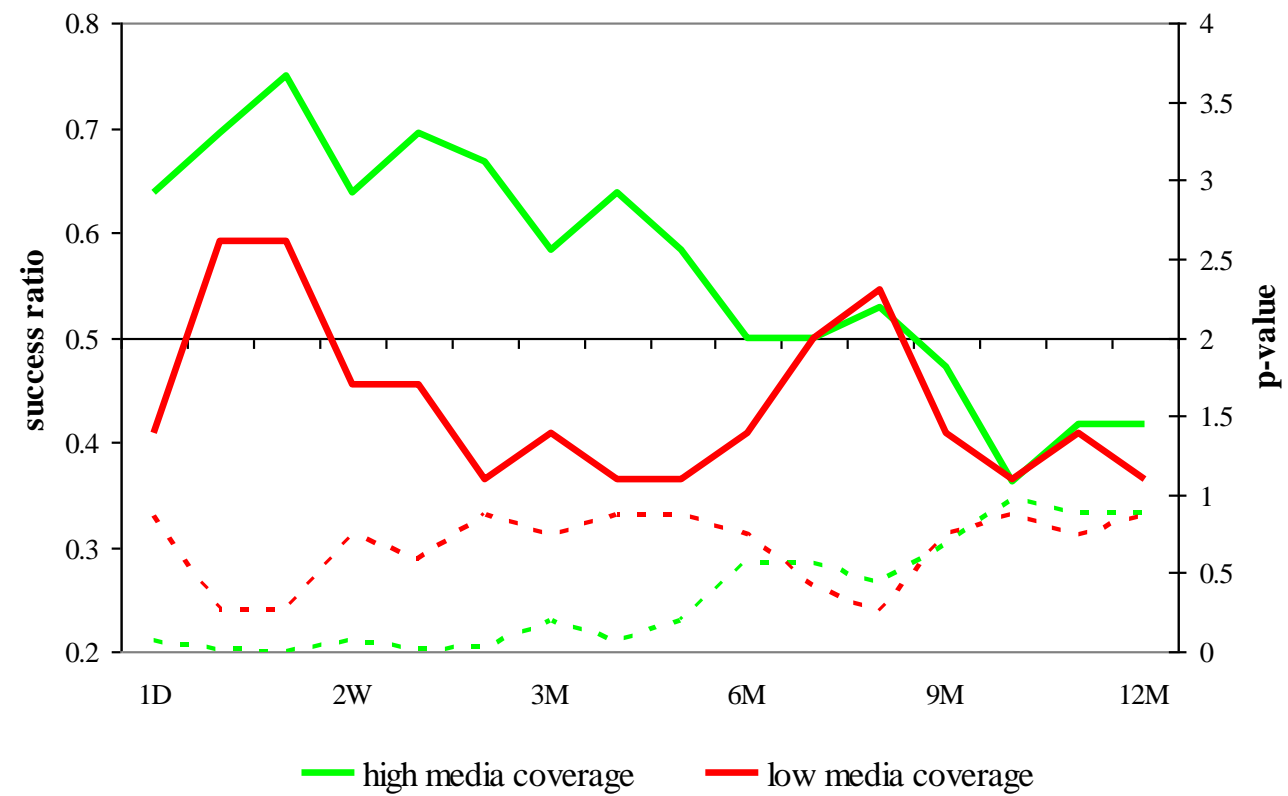

Notes: The figures show the success ratios of G7 meetings, based on the direction criterion, under alternative scenarios and over various time horizons ranging from 1 day (1D) to 12 months (12M) after G7 meetings. In Panel A, the green/light line gives the success ratio for G7 meetings when the reputation of the G7 before meetings, based on the semantic orientation of the media coverage, was high (relative to the average across all G7 meetings), while the red/dark line shows the success ratio of those when it was low. In Panel B, the corresponding results are provided for when the consensus among G7 policy-makers after the G7 meeting was high versus low (relative to the average across all G7 meetings), and in Panel C, for when the media coverage after G7 meetings was high (i.e. above average) versus low. Dashed lines show corresponding p-values for the various success ratios, using the right-hand $y$ axis. 


\section{Table 1: Determinants of G7 communiqués}

\begin{tabular}{lc} 
Dependent variable: & G7 communiqué \\
coef. & s.e. \\
\hline
\end{tabular}

G7 communiqué: strengthen currency pair $\left(\mathrm{y}_{\mathrm{t}}=+1\right)$

$\begin{array}{lll}\text { Misalignment } & 0.048 * * * & 0.016 \\ \text { Exchange rate volatility } & 3.489 * * * & 1.267 \\ \text { Interest rate diff. } & 0.027 & 0.096 \\ \text { Past currency trend } & 1.464 & 4.090\end{array}$

G7 communiqué: weaken currency pair $\left(\mathrm{y}_{\mathrm{t}}=-1\right)$

$\begin{array}{lcc}\text { Misalignment } & -0.052 * * * & 0.020 \\ \text { Exchange rate volatility } & 2.814 * * & 1.135 \\ \text { Interest rate diff. } & -0.086 & 0.063 \\ \text { Past currency trend } & -0.494 & 4.237\end{array}$

\begin{tabular}{lc}
\hline Observations & 228 \\
Cragg-Uhler $^{2}$ & 0.225 \\
\hline
\end{tabular}

Notes: The table shows the point estimates of a multinomial logit estimation with the dependent variable being whether a G7 communiqué intends to strengthen a particular G3 currency pair $\left(\mathrm{y}_{\mathrm{t}}=+1\right)$, weaken a currency pair $\left(y_{t}=-1\right)$, or expressed no view on that particular G3 bilateral exchange rate $\left(y_{t}=0\right)$. The baseline category for the estimation is $y_{t}=0$, so that the coefficients should be interpreted as the effect of an independent variable on the probability of the G7 expressing a view on whether a currency should strengthen or weaken as compared to it not expressing a view. The three G3 currency pairs are the USD-EUR, YEN-USD and YEN-EUR (DEM before 1999), which for 76 G7 meetings yields 228 observations in total. $* * *, * *$, and * indicate statistical significance at the $1 \%, 5 \%$, and $10 \%$ levels, respectively. 
Table 2: Inputs for calculation of semantic orientation of G7:

Number of hits in Factiva, around G7 meetings, 1975-2008

\begin{tabular}{lccrrr}
\hline \multicolumn{1}{c}{ \# of hits: } & G7 & pword & nword & $\begin{array}{c}\text { (G7 NEAR } \\
\text { pword })\end{array}$ & $\begin{array}{c}\text { (G7 NEAR } \\
\text { nword })\end{array}$ \\
\hline Total & 169,227 & $3,102,200$ & $1,850,349$ & 3,170 & 1,498 \\
& & & & & \\
Pre-G7 & 78,649 & $1,441,761$ & 859,958 & 1,285 & 646 \\
Post-G7 & 90,578 & $1,660,439$ & 990,391 & 1,885 & 852 \\
\hline
\end{tabular}

Source: Factiva; see text for explanations of individual entries. 
Table 3: Success criteria for G7 meetings - all G3 bilateral exchange rates

\begin{tabular}{cll|ll}
\hline & \multicolumn{2}{c|}{ Actual success } & \multicolumn{2}{c}{ Perceived success } \\
& Direction & Reversal & Direction & Reversal \\
& $\%$ success & $\%$ success & \% success & \% success \\
\hline $1 \mathrm{D}$ & 0.43 & 0.51 & 0.59 & 0.57 \\
$2 \mathrm{D}$ & $0.66 * *$ & 0.58 & 0.55 & 0.53 \\
$1 \mathrm{~W}$ & $0.69 * * *$ & $0.66 *$ & $0.67 * * *$ & $0.75 * * *$ \\
$2 \mathrm{~W}$ & 0.57 & $0.69 * *$ & 0.57 & 0.59 \\
$1 \mathrm{M}$ & $0.60 * *$ & $0.63 * *$ & $0.64 * *$ & 0.56 \\
$2 \mathrm{M}$ & 0.55 & 0.57 & $0.62 * *$ & 0.55 \\
$3 \mathrm{M}$ & 0.52 & 0.46 & $0.64 * *$ & 0.60 \\
$4 \mathrm{M}$ & 0.53 & $0.63 *$ & $0.64 * *$ & 0.60 \\
$5 \mathrm{M}$ & 0.50 & 0.50 & $0.67 * * *$ & $0.65 * *$ \\
$6 \mathrm{M}$ & 0.47 & 0.43 & $0.72 * * *$ & $0.73 * * *$ \\
$7 \mathrm{M}$ & 0.50 & 0.47 & $0.67 * * *$ & $0.68 * * *$ \\
$8 \mathrm{M}$ & 0.53 & 0.54 & $0.71 * * *$ & $0.68 * * *$ \\
$9 \mathrm{M}$ & 0.45 & 0.55 & $0.74 * * *$ & $0.76 * * *$ \\
$10 \mathrm{M}$ & 0.46 & 0.45 & $0.72 * * *$ & $0.71 * * *$ \\
$11 \mathrm{M}$ & 0.45 & 0.46 & $0.76 * * *$ & $0.76 * * *$ \\
$12 \mathrm{M}$ & 0.46 & 0.49 & $0.81 * * *$ & $0.78 * * *$ \\
\hline
\end{tabular}

Notes: The table shows the success criteria for the three bilateral G3 currency pairs jointly (USD-EUR, USD-YEN, YEN-EUR), for horizons ranging from 1 day (1D) to 12 months (12M). "\% success" gives the ratio of successes to failures over a particular horizon. "Actual success" gives the success ratios based on the exchange rate movements adjusted for the predicted change from the factor model; "perceived success" provides the corresponding success ratios for the unadjusted exchange rate changes, as explained in the text. ***,**, and * indicate statistical significance at the $1 \%, 5 \%$, and $10 \%$ levels, respectively, based on a sign test whether the number of successes $n_{+}$is larger than the number of failures $\mathrm{n}_{-}$, with the null hypothesis $\mathrm{n}_{+} \sim \operatorname{binomial}(\mathrm{n}, \mathrm{p}=0.5)$, with $\mathrm{n}$ as the number of events (G7 meetings) and $p$ the probability of success. 
Table 4: Success criteria for G7 meetings - exchange rate volatility

\section{A: G3 bilateral exchange rate volatility}

\begin{tabular}{cll}
\hline & $\begin{array}{c}\text { Volatility } \\
\% \text { success }\end{array}$ & $\begin{array}{c}\text { Abs. change } \\
\% \text { success }\end{array}$ \\
\hline 1D & $0.46 *$ & $0.41 * * *$ \\
$2 \mathrm{D}$ & 0.48 & $0.45 *$ \\
$1 \mathrm{~W}$ & 0.55 & 0.50 \\
$2 \mathrm{~W}$ & 0.55 & 0.48 \\
$1 \mathrm{M}$ & 0.56 & $0.43 * *$ \\
$2 \mathrm{M}$ & 0.57 & 0.50 \\
$3 \mathrm{M}$ & 0.54 & 0.49 \\
$4 \mathrm{M}$ & 0.55 & 0.50 \\
$5 \mathrm{M}$ & 0.48 & 0.51 \\
$6 \mathrm{M}$ & $0.45 *$ & 0.51 \\
$7 \mathrm{M}$ & 0.50 & 0.46 \\
$8 \mathrm{M}$ & 0.50 & 0.46 \\
$9 \mathrm{M}$ & 0.47 & 0.46 \\
$10 \mathrm{M}$ & 0.50 & 0.46 \\
$11 \mathrm{M}$ & 0.50 & 0.50 \\
$12 \mathrm{M}$ & 0.51 & 0.50 \\
\hline
\end{tabular}

\section{B: G3 nominal effective exchange rate (NEERs) volatility}

\begin{tabular}{cll}
\hline & Volatility & Abs. change \\
& $\%$ success & $\%$ success \\
\hline $1 \mathrm{D}$ & $0.44^{* *}$ & $0.45^{*}$ \\
$2 \mathrm{D}$ & 0.49 & 0.52 \\
$1 \mathrm{~W}$ & 0.52 & 0.50 \\
$2 \mathrm{~W}$ & 0.56 & 0.48 \\
$1 \mathrm{M}$ & 0.56 & $0.45 *$ \\
$2 \mathrm{M}$ & 0.55 & 0.50 \\
$3 \mathrm{M}$ & 0.46 & 0.49 \\
$4 \mathrm{M}$ & 0.52 & 0.49 \\
$5 \mathrm{M}$ & 0.46 & 0.50 \\
$6 \mathrm{M}$ & $0.42 * * *$ & 0.50 \\
$7 \mathrm{M}$ & 0.50 & 0.49 \\
$8 \mathrm{M}$ & 0.46 & 0.49 \\
$9 \mathrm{M}$ & 0.48 & 0.44 \\
$10 \mathrm{M}$ & 0.51 & 0.50 \\
$11 \mathrm{M}$ & 0.49 & 0.50 \\
$12 \mathrm{M}$ & 0.54 & 0.53
\end{tabular}

Notes: Panel A shows the direction criterion for the volatility of the three bilateral G3 currency pairs jointly (USD-EUR, USD-YEN, YEN-EUR), and Panel B for the NEERs of the US dollar, euro and yen, for horizons ranging from 1 day (1D) to 12 months $(12 \mathrm{M})$. "\% success" gives the ratio of successes to failures, "difference" gives the average change in the exchange rate volatility over a particular horizon. $* * *, * *$, and * indicate statistical significance at the $1 \%, 5 \%$, and $10 \%$ levels, respectively, based on a sign test whether the number of successes $n_{+}$is larger than the number of failures $n_{\text {., }}$ with the null hypothesis $n_{+} \sim \operatorname{binomial}(n, p=0.5)$, with $n$ as the number of events $(\mathrm{G} 7$ meetings) and $\mathrm{p}$ the probability of success. 
Table 5: Determinants of G7 success

Dependent variable:

\section{Actual success of G7}

(1)

(2)

(3)

(4)

coef. s.e. coef. s.e. coef. s.e. coef. s.e.

\begin{tabular}{|c|c|c|c|c|c|c|c|}
\hline \multicolumn{8}{|l|}{ A. G7 communication } \\
\hline Media coverage & 1.647 ** & $(0.709)$ & & & & $1.697 *$ & $(0.998)$ \\
\hline Intensity & 0.469 & $(0.359)$ & & & & 0.375 & $(0.42)$ \\
\hline Consensus & $2.321 * *$ & $(0.987)$ & & & & $2.597 * *$ & $(1.239)$ \\
\hline Change communique & -0.094 & $(0.674)$ & & & & -0.222 & $(0.828)$ \\
\hline \multicolumn{8}{|l|}{ B. G7 reputation } \\
\hline Pre G7 meeting & & & $4.234 * * \quad(1.836)$ & & & $3.778 *$ & $(2.085)$ \\
\hline \multicolumn{8}{|l|}{ C. Policy support } \\
\hline Monetary policy & & & & -0.014 & $(0.113)$ & 0.001 & $(0.127)$ \\
\hline Actual interventions & & & & $1.860 * * *$ & $(0.681)$ & $1.495 *$ & $(0.808)$ \\
\hline \multicolumn{8}{|l|}{ D. Market conditions } \\
\hline Misalignment & & & & $0.042 * *$ & $(0.018)$ & $0.039 *$ & $(0.022)$ \\
\hline Volatility & & & & -1.517 & $(2.089)$ & -1.769 & $(2.485)$ \\
\hline Observations & \multicolumn{2}{|l|}{58} & 58 & \multicolumn{2}{|l|}{58} & \multicolumn{2}{|l|}{58} \\
\hline McKelvey \& Zavoina's $\mathrm{R}^{2}$ & \multicolumn{2}{|c|}{0.231} & 0.142 & \multicolumn{2}{|c|}{0.283} & \multicolumn{2}{|c|}{0.518} \\
\hline Cragg-Uhler $\mathrm{R}^{2}$ & \multicolumn{2}{|l|}{0.223} & 0.137 & \multicolumn{2}{|l|}{0.288} & \multicolumn{2}{|c|}{0.471} \\
\hline
\end{tabular}

Notes: The dependent variable is the success $(y=1)$ or failure $(y=0)$ of $G 7$ meetings in moving the three bilateral G3 currency pairs in the desired direction (i.e. using the direction criterion) over a 1-month horizon, with exchange rates movements corrected for the "bias" over this horizon. The empirical model is a logit specification. $* * *, * *$, and * indicate statistical significance at the $1 \%, 5 \%$, and $10 \%$ levels, respectively. 
Table 6: Determinants of G7 success - robustness

\begin{tabular}{|c|c|c|c|c|c|c|}
\hline \multirow[t]{3}{*}{ Dependent variable: } & \multicolumn{6}{|c|}{ Actual success of G7 } \\
\hline & \multicolumn{2}{|c|}{ All currencies } & \multicolumn{2}{|c|}{ 2-week horizon } & \multicolumn{2}{|c|}{ 3-month horizon } \\
\hline & coef. & s.e. & coef. & s.e. & coef. & s.e. \\
\hline \multicolumn{7}{|l|}{ A. G7 communication } \\
\hline Media coverage & $0.959 * *$ & $(0.478)$ & $0.942 * *$ & $(0.466)$ & -0.111 & $(0.815)$ \\
\hline Intensity & 0.102 & $(0.242)$ & 0.054 & $(0.243)$ & 0.239 & $(0.399)$ \\
\hline Consensus & $2.277 * * *$ & $(0.664)$ & $1.78 * * *$ & $(0.642)$ & $1.805 *$ & $(0.973)$ \\
\hline Change communique & 0.277 & $(0.47)$ & 0.445 & $(0.464)$ & -0.632 & $(0.736)$ \\
\hline \multicolumn{7}{|l|}{ B. G7 reputation } \\
\hline Pre G7 meeting & $3.049 * *$ & $(1.187)$ & $3.312 * * *$ & $(1.205)$ & $3.587 *$ & (1.979) \\
\hline \multicolumn{7}{|l|}{ C. Policy support } \\
\hline Monetary policy & 0.116 & $(0.075)$ & 0.039 & $(0.071)$ & -0.012 & $(0.11)$ \\
\hline Actual interventions & -0.146 & $(0.439)$ & $-1.074 * *$ & $(0.444)$ & 0.543 & $(0.719)$ \\
\hline \multicolumn{7}{|l|}{ D. Market conditions } \\
\hline Misalignment & $0.051 * * *$ & $(0.014)$ & $0.044 * * *$ & $(0.014)$ & 0.024 & $(0.019)$ \\
\hline Volatility & 0.349 & $(0.97)$ & 0.112 & $(0.962)$ & 2.414 & $(2.307)$ \\
\hline Observations & \multicolumn{2}{|c|}{116} & \multicolumn{2}{|l|}{58} & \multicolumn{2}{|c|}{58} \\
\hline McKelvey \& Zavoina's R ${ }^{2}$ & \multicolumn{2}{|c|}{0.316} & \multicolumn{2}{|c|}{0.277} & \multicolumn{2}{|c|}{0.304} \\
\hline Cragg-Uhler $\mathrm{R}^{2}$ & \multicolumn{2}{|c|}{0.295} & \multicolumn{2}{|c|}{0.256} & \multicolumn{2}{|c|}{0.282} \\
\hline
\end{tabular}

Notes: The dependent variable is the success $(y=1)$ or failure $(y=0)$ of $G 7$ meetings in moving G3 exchange rates in the desired direction (i.e. using the direction criterion) over a 1-month horizon, with exchange rates movements corrected for the "bias" over this horizon. The first column shows the findings using both bilateral and effective G3 exchange rates. The second and third sets of columns give the estimates for the 3 bilateral currency pairs when using different time horizons of 2 weeks and 3 months, respectively. The empirical model is a logit specification. $* * *, * *$, and $*$ indicate statistical significance at the $1 \%, 5 \%$, and $10 \%$ levels, respectively. 
Table 7: Evolution of G3 consensus around G7 meetings

\begin{tabular}{lccccc}
\hline \multicolumn{5}{c}{ Consensus among G3 } \\
& Pre-G7 meeting & Post-G7 meeting & \\
& mean & s.e. & mean & s.e. & signif. \\
\hline Periods: & & & & & \\
$1975-2008$ & 0.440 & 0.038 & 0.616 & 0.036 & $* * *$ \\
$1975-1995$ & 0.334 & 0.056 & 0.661 & 0.048 & $* * *$ \\
$1996-2008$ & 0.543 & 0.049 & 0.571 & 0.052 & \\
\hline
\end{tabular}

Notes: The table shows summary statistics - the mean and the standard error - for the consensus of G3 policy-makers on exchange rates during the month before G7 meetings ("Pre-G7 meeting") versus the month after G7 meetings ("Post-G7 meeting"). Using a t-test, "signif." reveals whether this difference is statistically significant. $* * *, * *$, and $*$ indicate statistical significance at the $1 \%, 5 \%$, and $10 \%$ levels, respectively. 


\section{Table 8: Determinants of G3 consensus after G7 meetings}

\begin{tabular}{lcccc}
\hline Dependent variable: & \multicolumn{3}{c}{ Consensus among G3 } \\
& \multicolumn{2}{c}{$(1)$} & \multicolumn{2}{c}{$(2)$} \\
& coef. & s.e. & coef. & s.e. \\
\hline Change communique & -0.122 & $(0.111)$ & -0.113 & $(0.069)$ \\
Monetary policy & 0.005 & $(0.019)$ & 0.01 & $(0.01)$ \\
Actual interventions & 0.123 & $(0.107)$ & $0.187 * * *$ & $(0.056)$ \\
Misalignment & -0.002 & $(0.003)$ & 0.000 & $(0.002)$ \\
Volatility & -0.306 & $(0.359)$ & 0.156 & $(0.147)$ \\
Observations & \multicolumn{3}{c}{58} & \multicolumn{2}{c}{228} \\
$\mathrm{R}^{2}$ & \multicolumn{2}{c}{0.06} & \multicolumn{2}{c}{0.07} \\
\hline
\end{tabular}

Notes: The dependent variable of the model is the degree of consensus among G3 policy-makers on exchange rates during the month after G7 meetings, and its determinants. Model (1) is for only those G7 meetings which issued a communiqué with guidance on exchange rate levels, while model (2) includes all $76 \mathrm{G} 7$ meetings for the 3 bilateral currency pairs. ***,**, and * indicate statistical significance at the $1 \%, 5 \%$, and $10 \%$ levels, respectively. 
Table 9: Determinants of G7 reputation

Dependent variable:

Semantic orientation of G7

(1)

(2)

(3)

coef. s.e. coef. s.e. coef. s.e.

Success:

Actual success $\quad 0.096 * * *(0.035)$

"Perceived" success $\quad 0.062 *(0.035)$

\section{Focus:}

G7 no focus dummy

$-0.041 * * \quad(0.018)$

Determinants:

A. G7 communication

Media coverage

Intensity

Consensus

Change communique

B. G7 reputation

Pre G7 meeting

C. Policy support

Monetary policy

Actual interventions

\begin{tabular}{ccccc}
$0.029 * *$ & $(0.013)$ & $0.025 *$ & $(0.013)$ \\
$0.015 * *$ & $(0.007)$ & $0.013 *$ & $(0.007)$ \\
0.015 & $(0.018)$ & 0.014 & $(0.018)$ \\
-0.01 & $(0.019)$ & -0.009 & $(0.018)$ \\
& & & \\
$0.509 * * *$ & $(0.038)$ & $0.485 * * *$ & $(0.039)$ \\
& & & \\
0.003 & & $(0.003)$ & 0.002 & $(0.003)$ \\
0.011 & $(0.015)$ & 0.011 & $(0.015)$ \\
& & & \\
-0.001 & & $(0.001)$ & -0.001 & $(0.001)$ \\
0.051 & $(0.041)$ & 0.050 & $(0.041)$ \\
\multicolumn{3}{c}{58} & & \multicolumn{3}{c}{228} \\
0.49 & & \multicolumn{3}{c}{0.51}
\end{tabular}

Notes: The dependent variable is the semantic orientation of the media coverage of G7 meetings in the 2 months after the respective meetings. Models (1) and (2) are only those G7 meetings in which the communiqué expresses a view on exchange rate levels, while model (3) includes all G7 meetings. This last model includes the variable "G7 no focus dummy" which is equal to one if the G7 communiqué does not make a statement about desired exchange rate levels, and zero otherwise. ***, **, and * indicate statistical significance at the $1 \%, 5 \%$, and $10 \%$ levels, respectively. 


\section{APPENDIX}


Table A.1: Summary statistics of determinants

\begin{tabular}{lcccc}
\hline & Mean & Std. Dev. Min & Max \\
\hline A. G7 communication & & & & \\
$\quad$ Media coverage & 0.904 & 0.560 & 0 & 2.379 \\
$\quad$ Intensity & 1.204 & 0.998 & 0 & 4.469 \\
$\quad$ Consensus & 0.336 & 0.389 & 0 & 1 \\
$\quad$ Change communique & 0.171 & 0.377 & 0 & 1 \\
B. G7 reputation & & & & \\
$\quad$ Pre G7 meeting & 0.031 & 0.177 & -0.320 & 0.490 \\
$\quad$ Post G7 meeting & 0.099 & 0.138 & -0.140 & 0.450 \\
C. Policy support & & & & \\
$\quad$ Monetary policy & -0.543 & 2.501 & -5.744 & 6.023 \\
$\quad$ Actual interventions & 0.303 & 0.460 & 0 & 1 \\
D. Market conditions & & & & \\
$\quad$ Misalignment & 1.816 & 13.416 & -28.62 & 46.08 \\
$\quad$ Volatility & 0.518 & 0.199 & 0.092 & 1.346 \\
\hline
\end{tabular}

Table A.2: Correlations across determinants

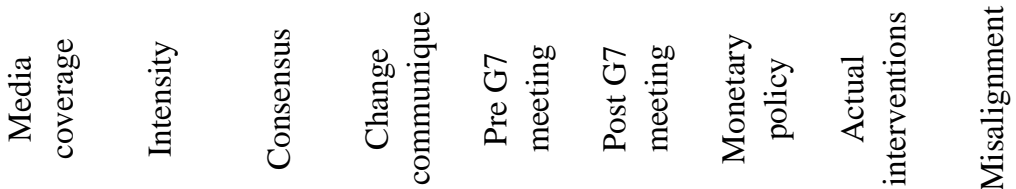

\begin{tabular}{|c|c|c|c|c|c|c|c|c|c|}
\hline \multicolumn{10}{|l|}{ A. G7 communication } \\
\hline Media coverage & 1 & & & & & & & & \\
\hline Intensity & 0.210 & 1 & & & & & & & \\
\hline Consensus & -0.074 & 0.017 & 1 & & & & & & \\
\hline Change communique & 0.032 & -0.200 & -0.069 & 1 & & & & & \\
\hline \multicolumn{10}{|l|}{ B. G7 reputation } \\
\hline Pre G7 meeting & 0.004 & 0.065 & -0.031 & 0.023 & 1 & & & & \\
\hline Post G7 meeting & 0.151 & 0.177 & 0.031 & -0.006 & 0.679 & 1 & & & \\
\hline \multicolumn{10}{|l|}{ C. Policy support } \\
\hline Monetary policy & -0.025 & -0.037 & 0.099 & -0.072 & -0.031 & 0.027 & 1 & & \\
\hline Actual interventions & -0.017 & 0.027 & 0.204 & 0.157 & 0.116 & 0.124 & 0.048 & 1 & \\
\hline \multicolumn{10}{|l|}{ D. Market conditions } \\
\hline Misalignment & 0.064 & 0.018 & -0.049 & 0.022 & 0.015 & -0.035 & -0.008 & -0.045 & 1 \\
\hline Volatility & 0.204 & 0.025 & 0.041 & 0.077 & 0.061 & 0.122 & -0.035 & -0.039 & -0.001 \\
\hline
\end{tabular}


Figure A.1: Examples of three alternative exchange rate forecasts for the USD-EUR on 1 May 2008

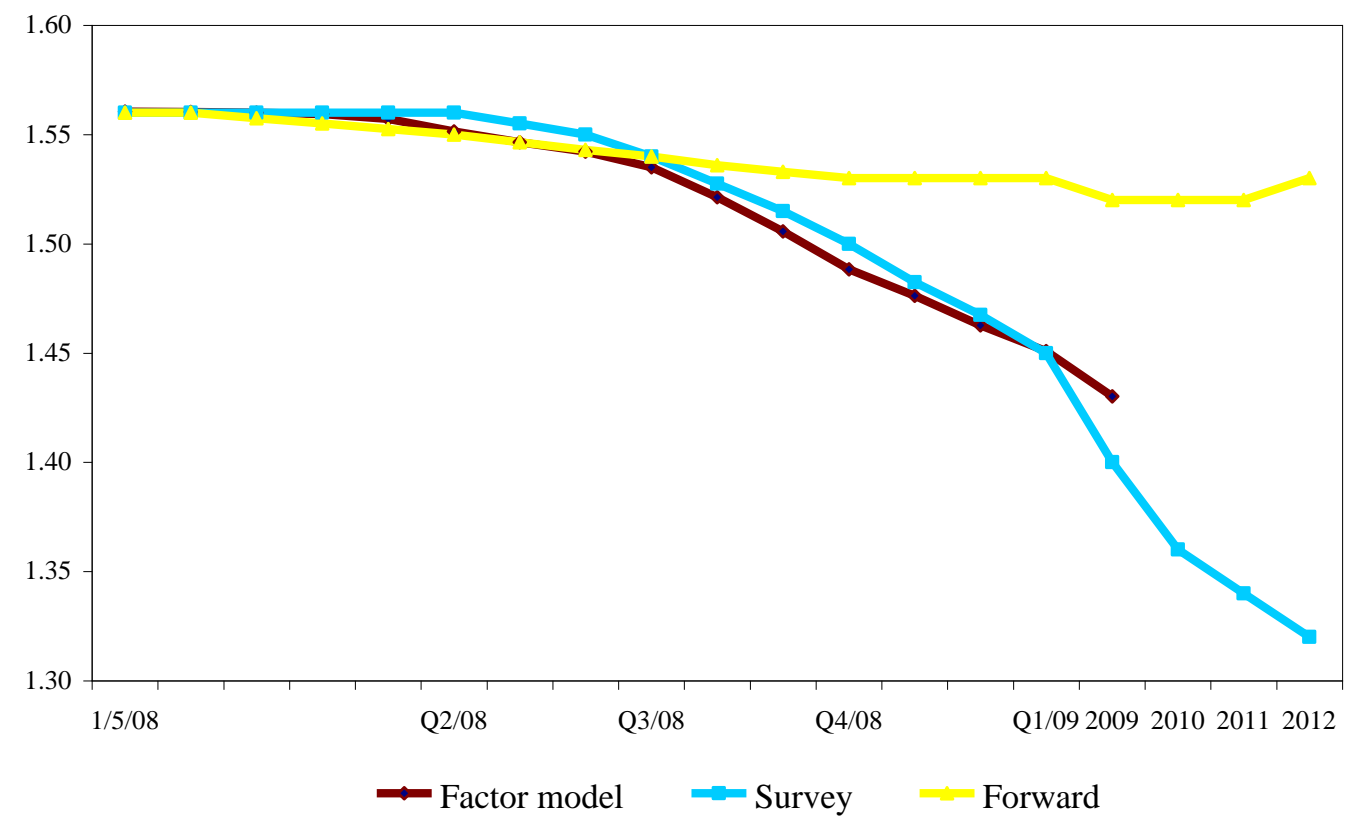

Notes: The figure shows forecasts for the US dollar - euro exchange rate on 1 May 2008 from three different sources: (1) Bloomberg surveys of 50-60 market participants, (2) Current forward contracts, and (3) the factor model with four factors, as explained in the text. For the first two, only those horizons shown on the $\mathrm{x}$-axis are available. For the factor model, forecasts are up to 12 months. 
Figure A.2: Factor model for determination of counterfactual

\section{A: Coefficient estimates}

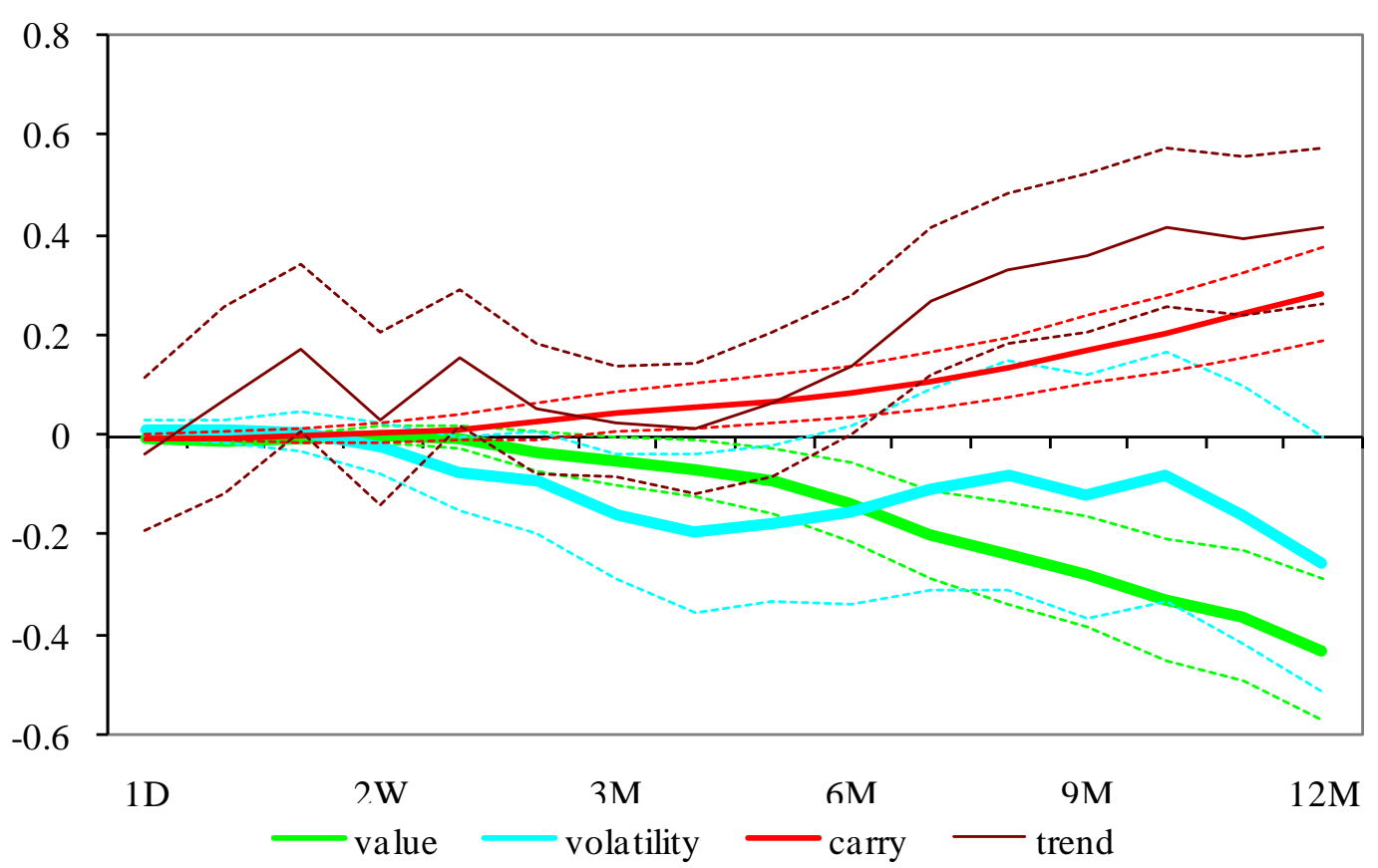

\section{B: Explanatory power}

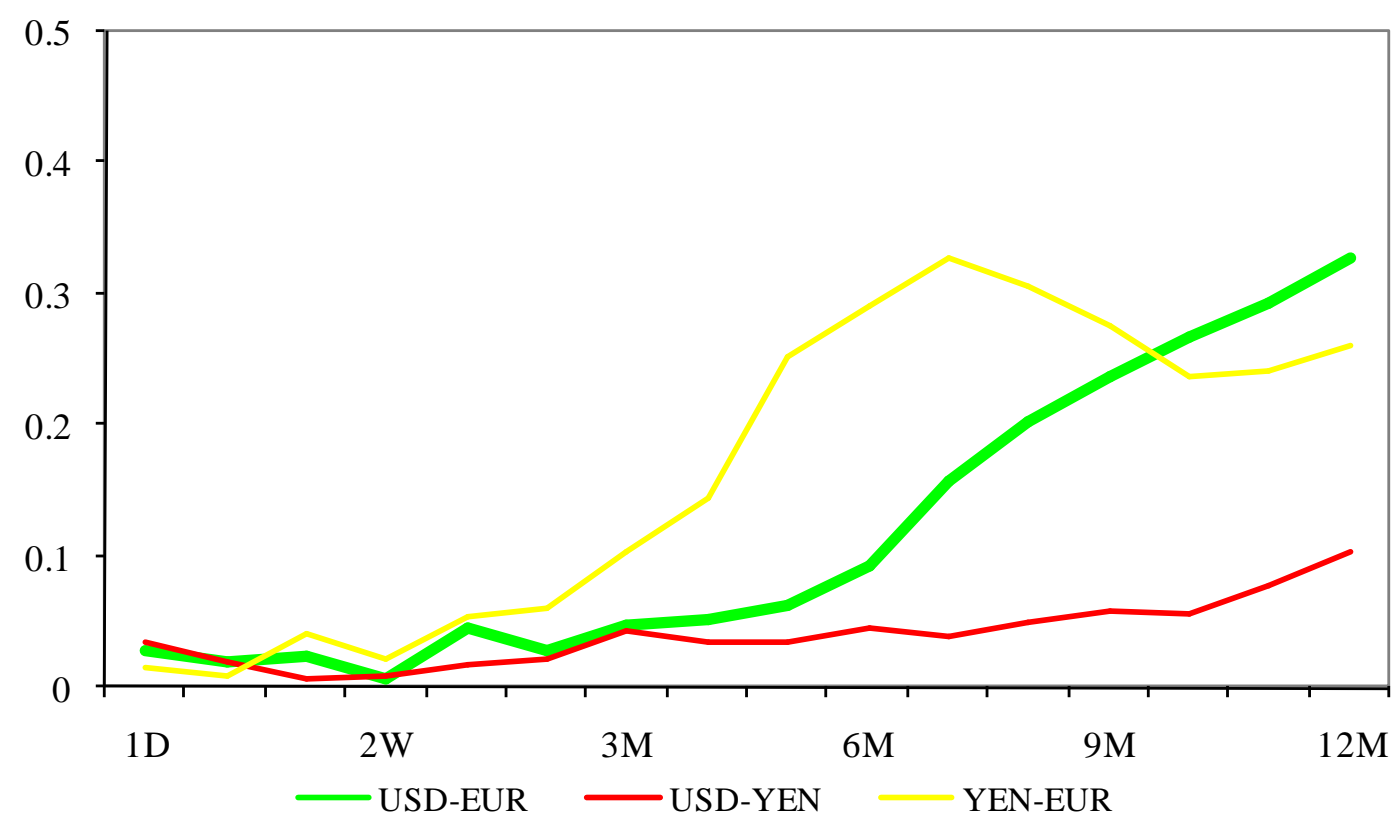

Notes: Panel A gives the coefficients and $90 \%$ confidence intervals for each of the four factors of the factor model for the USD-EUR exchange rate, estimated at horizons ranging from 1 day to 12 months. Panel B provides the R-squared of the model estimates at these different horizons for each of the G3 currency pairs. 


\section{Appendix A: Consensus, cacophony and communication across G3 policy- makers}

This Appendix outlines the measurement and classification of statements of individual G3 policy-makers around G7 meetings. The objective is to obtain two such measures: the first one for the intensity of G3 communication after G7 meetings as a proxy for the information content and impact of such communication; and a second one for the disagreement or cacophony among G3 policy-makers.

The starting point is to extract all statements by relevant G3 policy-makers in the period around G7 meetings, which is chosen to be two months before and two months afterwards, i.e. using the same time window as for G7 reputation. The newswire provider Reuters News is taken to extract all statements on exchange rates during that time window by central bank governors and finance ministry officials.

As exchange rate policy in the United States and in Japan is primarily in the domain of the treasury departments, all statements of the Treasury Secretary, the Deputy Treasury Secretary and the Chairman of the Federal Reserve for the United States; and for Japan all statements of the Finance Minister and the Vice Finance Minister for International Affairs, plus the Governor and Deputy Governors of the Bank of Japan, are included. Exchange rate policy for Germany prior to 1999 and for the euro area since 1999 has been primarily the responsibility of the respective central banks, so that statements by members of the Bundesbank Zentralbankrat for before 1999 and the ECB Governing Council since 1999 have been extracted and included. Nevertheless, the finance ministries share responsibility for communication on exchange rates in the euro area, so that they do play a role in the overall process.

The following search criteria are used to extract such statements: first, the name or title of the policy maker, and second, the term "exchange rate" or the name of the currency. Only the first of each reports or articles on a statement is included in order to avoid double-counting.

The next step is the classification of the statements into those that aim at strengthening a particular currency $\left(C_{t}=+1\right)$, those that intend to weaken it $\left(C_{t}=-1\right)$, and neutral statements $\left(\mathrm{C}_{\mathrm{t}}=0\right)$. The systematic analysis and classification of statements comes from a related literature in linguistics to the one described in the previous sub-section. The objective is not only to systematically extract the content of language but also to reduce the possibility of false classification. Statements were classified by several people following the extraction criteria described above. In most cases, the classification of statements on exchange rates by G3 policy-makers is unanimous. In cases of ambiguity, statements were discarded.

As in the discussion in the previous sub-section, several caveats apply to such a classification of language. In particular, the statements extracted and classified may include an interpretation or reporting not intended by a policy-maker, hence possibly inducing an unintended currency reaction; or statements may not be reported. However, in defense of the chosen methodology, the objective here is to analyze the information that does become available to financial markets and how they react to it.

The final step of the methodology is to measure the intensity as well as the degree of consensus among G3 policy-makers. The intensity of G3 communication is proxied as the number of statements by G3 policy-makers around a G7 meeting, normalized by the average number of such statements in the five years surrounding the respective statement in order to correct for the increasing coverage of Reuters News over time. 
The more tricky issue is the measurement of consensus across G3 policy-makers. For this purpose, I use the measure of consensus on monetary policy used in Jansen and de Haan (2004) and Ehrmann and Fratzscher (2007), which applied to exchange rate communication is defined as follows:

$$
\Omega=1-\left(\frac{\sum_{i=1}^{N-1} \sum_{j=i+1}^{N}\left|C_{i}-C_{j}\right|}{1 / 2 \cdot\left(N^{2}-D\right)}\right)
$$

with $C$ defined as a $[-1,0,+1]$ variable, as outlined above, $N$ the total number of G3 statements in the period around a G7 meeting, and D as a dummy that takes the value of one if $\mathrm{N}$ is an odd number and zero if it is even. The intuition of the measure is that the higher the disagreement and dispersion in a pair of exchange rate statements $i$ and $j$ across G3 policymakers, the larger is $\left|C_{i}-C_{j}\right|$, and thus the smaller is the measure $\Omega$. Hence $\Omega$ is the proxy for G3 consensus about exchange rates for a particular G7 meeting, bounded by $\Omega=0$ implying a maximum of disagreement and $\Omega=1$ as full consensus.

Figure A.3 shows the evolution of consensus on exchange rate developments across G3 policy-makers in the time windows around G7 meetings. It shows no clear time trend, though there are some periods where G3 policy-makers appear to have been mostly in agreement, while in others the opposite was the case.

\section{Figure A.3: Consensus among G3 policy-makers around G7 meetings}

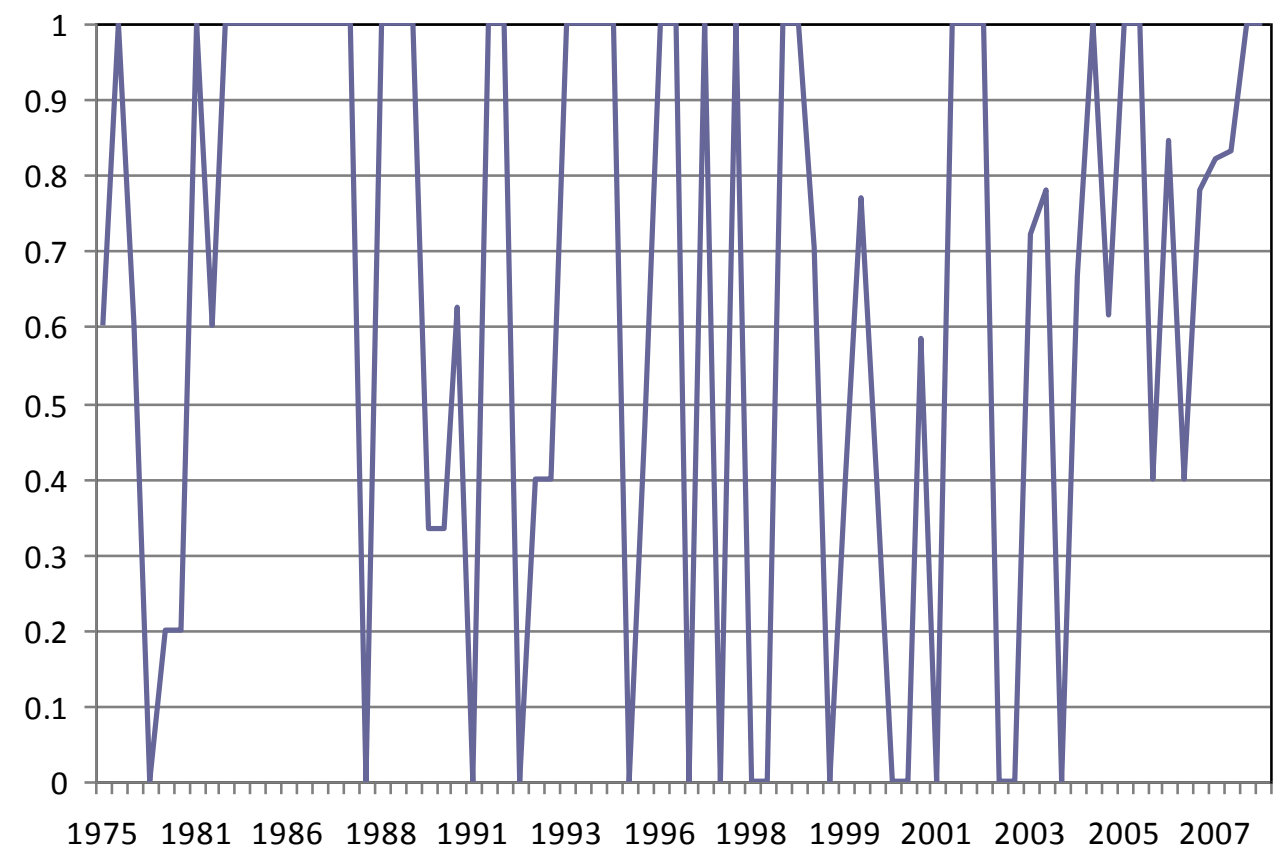

Notes: The figure shows the degree of consensus across G3 policy-makers during the two months before to two months after each G7 meeting, based on the communication of the individual policymakers. 